Revista de

Contabilidade e Organizações www.rco.usp.br
DOI: http://dx.doi.org/10.11606/issn.1982-6486.rco.2021.182882
Journal of

Accounting and

Organizations

\title{
Percepção de pós-graduandos sobre os motivos que contribuiriam para a evasão de estudantes dos cursos stricto sensu em Contabilidade
}

\author{
Student perception about reasons behind attrition in accounting graduate programs
}

Victor Hugo Pereira ${ }^{a}$, Jacqueline Veneroso Alves da Cunha ${ }^{a}$, Bruna Camargos Avelino ${ }^{a}$, Edgard Bruno Cornacchione Junior ${ }^{\mathrm{b}}$

${ }^{a}$ Universidade Federal de Minas Gerais - Brasil

${ }^{b}$ Univerisdade de São Paulo - Brasil

\section{Palavras-chave}

Evasão.

Mestrado.

Doutorado.

Ciências Contábeis.

\begin{abstract}
Resumo
Este estudo teve como objetivo principal identificar a percepção de pós-graduandos sobre os motivos que contribuiriam para a evasão de estudantes dos cursos de pós-graduação stricto sensu em Contabilidade. Participaram da pesquisa 619 pósgraduandos que responderam ao questionário disponibilizado online. Os resultados evidenciaram que, para os discentes matriculados nos cursos de Mestrado em Contabilidade, as dificuldades para acompanhar o curso devido ao tempo necessário para os estudos foi indicado como o motivo que mais contribuiria para a evasão. Os estudantes matriculados nos cursos de Doutorado não indicaram motivos que representassem uma contribuição de alto grau na propensão para a evasão. De um modo geral, destacaram que um motivo que contribuiria fortemente para a evasão seria as dificuldades para acompanhar o curso devido ao tempo necessário para os estudos. Isto reforça a necessidade de discussões sobre o tema, com o intuito de apoiar os estudantes ao longo da realização de suas atividades acadêmicas. Ao reconhecerem possíveis dificuldades relatadas pelos discentes, os membros das instituições de ensino têm a oportunidade de buscar alternativas para auxiliar o estudante a lidar com situações de desconforto na universidade.
\end{abstract}

\begin{abstract}
This study had as main objective to identify a perception of graduation students about the reasons that would contribute to the evasion of students from stricto sensu courses in Accounting. 619 graduate students participated in the survey and answered the questionnaire available online. The results showed that, for students enrolled in the Master's Degree in Accounting, the difficulties to follow the course due to the time needed for studies was indicated as the reason that most contributed to the dropout. Students enrolled in Doctoral Degree did not indicate reasons that would represent a high degree of contribution to the propensity for dropout. In general, highlighted that a reason that would strongly contribute to the dropout would be the difficulties in keeping up with the course due to the time needed for studies. This reinforces the need to exercise on the subject, in order to support studies throughout the performance of their academic activities. When recognizing possible difficulties reported by the students, the members of the educational institution have the opportunity to seek alternatives to help the student to deal with discomfort situations at the university.
\end{abstract}

\section{Implicações práticas}

Os achados deste estudo contribuem para a gestão acadêmica, pois possibilitam a compreensão dos fatores que levariam à evasão em níveis mais elevados de ensino, visto o impacto na avaliação do curso e as perdas de investimentos públicos e privados.

Copyright (C) 2021 FEA-RP/USP. Todos os direitos reservados
Recebido: 05 de março de 2021

Aprovado: 02 de agosto de 2021

Publicado: 21 de outubro de 2021

Agradecemos ao Conselho Nacional de Desenvolvimento Científico e Tecnológico (CNPq) pelo apoio financeiro.

In Memoriam

Saudade que Victor nos deixa é enorme e equivalente ao seu brilhantismo acadêmico e à sua plenitude humana, especialmente na integração agradável e maturidade nos relacionamentos.

Autor correspondente: Tel. (31) 3409-7275

E-mail: jvacbr@yahoo.com.br (J. V. A. da Cunha); bcavelino@gmail.com (B. C. Avelino); edgardbc@usp.br (E. B. Cornacchione Junior)

Universidade Federal de Minas Gerais. Av. Antonio Carlos 6627, Pampulha, Belo Horizonte/MG - 31270901, Brasil.

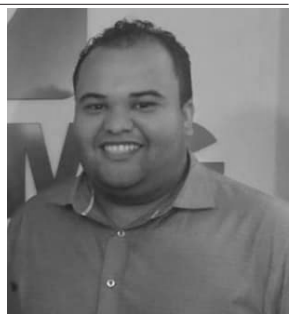




\section{INTRODUÇÃO}

A busca pelos motivos que culminam na evasão de estudantes tem sido objeto de pesquisas nacionais e internacionais, com atenção especial aos cursos superiores (Gomes, 1998; Vergidis \& Panagiotakopoulos, 2002; Andriola et al., 2006; Adachi, 2009; Alves \& Alves, 2012; Castro, 2012; Díaz et al., 2012; Barbosa, 2013; Sales, 2013; Silva, 2013; Slhessarenko et al., 2014; Camelo Neto, 2014; Pereira et al., 2014; Rafael et al., 2015; Silva, 2016; Gama, 2015; Ambiel, 2015; Barbosa et al., 2016; Cornélio et al., 2016; Feitosa, 2016; Bisinoto \& Arenas, 2016; Ambiel et al., 2016).

Há estudos que buscam indicadores que explicam o fenômeno do abandono de estudantes (Canziani, 2015; Lima \& Zago, 2016; Vitelli 2013); que avaliam a evasão diante de políticas públicas da educação, como o Sistema de Seleção Unificado (SISU) (Gilioli, 2016; Machado \& Szerman, 2017); em diferentes instituições (Braga et al., 2003; Palharini, 2004; Adachi, 2009); na área de exatas (Lima, 2013; Gomes, 2015; Silva, 2016; Freitas et al., 2017); focados nas licenciaturas (Vitelli, 2013; Rocha, 2015; Massi \& Villani, 2015); e, ainda, aqueles que traçam estratégias para minimizar o fenômeno da evasão (Tontini \& Walter, 2014).

Assim como em outras áreas, na Contabilidade a evasão tem crescido ao longo dos anos. Conforme informações disponibilizadas em 2018 pelo Instituto Nacional de Estudos e Pesquisas Educacionais (INEP), é possível verificar que, em 2014, 953 instituições ofertaram o curso de graduação em Ciências Contábeis: o número de matrículas foi de 353.597 e o número de estudantes que evadiram foi de 131.338 , representando mais de $37 \%$ dos ingressantes. Em 2016, já eram 995 instituições ofertando o curso, com 355.425 matrículas e o número de evadidos atingindo 159.410. Comparando os anos de 2014 e 2016, evidencia-se um aumento de 21,37\% na taxa de evasão dos cursos de graduação em Ciências Contábeis.

Em se tratando dos cursos stricto sensu em Contabilidade, a primeira turma de Mestrado em Contabilidade, na Universidade de São Paulo (USP), foi formada em 1974 e de Doutorado em 1977 (Cunha, 2007). Ao longo dos anos, houve um crescimento significativo no número de Mestrados e de Doutorados em Contabilidade reconhecidos pela Coordenação de Pessoal de Nível Superior (Capes) no Brasil, o que por si só já justifica o estudo da evasão nesse nível de ensino.

Por meio das informações disponibilizadas pela Capes em relação ao último quadriênio (2013-2016), o número de instituições de Ensino Superior que ofertavam cursos de Pós-Graduação stricto sensu cresceu de $15,73 \%$ para $17,32 \%$ no período. Em relação ao Mestrado profissional, o crescimento no número de estudantes matriculados foi de 56,77\%, no mesmo período. Em 2017, eram 30 cursos de pós-graduação ofertando o Mestrado em Contabilidade e, dentre estes, 14 também ofertavam o Doutorado (Capes, 2017). De acordo com Miranda et al. (2012), esse crescimento deverá alterar significativamente a dinâmica do processo de ensino-aprendizagem em Contabilidade no Brasil.

Ainda entre 2013 e 2016, o percentual de evadidos foi de 22,53\% em 2013, 20,36\% em 2014, 18,35\% em 2015 e 23,96\% em 2016. Nos cursos de Mestrado acadêmico, nos quais o aumento de estudantes matriculados foi de 14,36\%, o percentual de desligamentos foi de 14,45\% em 2013; 12,93\% em 2014; 11,79\% em 2015 e 10,63\% em 2016. Nos cursos de Doutorado, o número de estudantes matriculados também cresceu, atingindo $21,72 \%$ de aumento. O percentual de evadidos foi de $16,17 \%$ em 2013; $13,75 \%$ em 2014; $12,07 \%$ em 2015; e $10,55 \%$ em 2016. Apesar do alto percentual de evasão na pós-graduação stricto sensu no Brasil, não foram encontrados estudos que investigassem, especificamente, os motivos que contribuiriam para tal cenário. Na literatura internacional, também não são encontrados muitos trabalhos que abordam o tema no ambiente da pós-graduação (Golde, 1998; Zewotin et al., 2015).

Neste contexto, e considerando, principalmente, o crescimento no número de cursos de Mestrado e de Doutorado em Contabilidade no país, torna-se fundamental conhecer os motivos que contribuiriam para a evasão de estudantes nestas modalidades de ensino. Assim, a questão de pesquisa que norteou este estudo foi: Quais são os motivos que contribuiriam para a evasão de estudantes dos cursos de pós-graduação stricto sensu em Contabilidade do país?

O objetivo deste estudo foi identificar a percepção de pós-graduandos sobre os motivos que contribuiriam para a evasão de estudantes dos cursos de pós-graduação stricto sensu em Contabilidade. Adicionalmente, buscouse verificar os motivos que levaram os pós-graduandos a ingressarem nos cursos de pós-graduação stricto sensu em Contabilidade.

A escolha deste tema decorreu da necessidade de se desenvolver estudos mais específicos nos cursos de Mestrado e Doutorado em Contabilidade, de modo a compreender melhor os motivos que levariam os estudantes à evasão, especialmente para permitir intervenções que ajudem a mantê-los no curso. Com isso, este estudo pretende estimular outras pesquisas na área, servindo de ponto de partida, também, para análise em outras áreas do conhecimento. 


\section{PLATAFORMA TEÓRICA}

\subsection{Teorias da evasão universitária}

Os estudos iniciais sobre evasão de estudantes foram desenvolvidos por Spady (1970), Tinto (1993, 1997), Bean (1980), Pascarella e Terenzini (1980) e Astin (1985). A teoria do processo de abandono desenvolvida por Spady $(1970,1971)$ enfatiza o processo de integração dos atributos, dos valores, dos interesses, das habilidades e das atitudes do estudante no ambiente escolar. Desse modo, havendo uma relação harmoniosa entre o estudante e a escola, o processo de assimilação social e acadêmico será satisfatório e suas possibilidades de permanência serão maiores, visto que, quanto mais satisfeito o estudante estiver, maior será o seu comprometimento com a instituição, culminando em evasão menor.

O modelo retratado anteriormente foi revisado por Spady em 1971, uma vez que existiam divergências baseadas no gênero dos estudantes. O autor observou que, para os homens, o desempenho em relação às notas era 0 fator mais importante para a desistência do curso, enquanto para as mulheres, o compromisso com a instituição era o fator determinante para o abandono. Em seu modelo ajustado, houve também a inclusão das relações estruturais no construto suporte de amigos. As relações estruturais podem ser influenciadas pela relação entre professores e estudantes, pela relação com os demais estudantes do gênero oposto, pelo desempenho acadêmico e pelo suporte de amigos.

A Teoria de Integração do Estudante, desenvolvida por Tinto (1975), se propõe a elucidar as particularidades e os processos que influenciam na decisão de um estudante em desistir de um curso. Além disso, busca compreender como esses processos confluem para a decisão de abandono ou permanência. Para o autor, a escolha do estudante por permanecer ou não no curso é consequência da relação entre ele e a própria instituição, passando por conceitos fundamentais, como a integração acadêmica e social à instituição. Assim, para Tinto (1975), os estudantes ingressam na instituição munidos de uma série de características como raça, gênero, habilidades passadas adquiridas ao longo de sua jornada, experiências prévias adquiridas, desempenho acadêmico e social e de um contexto familiar. Cada uma dessas características impacta direta ou indiretamente no desempenho do estudante na instituição e no curso matriculado.

Em 1993, Tinto realizou alterações que refinaram o modelo anterior, considerando, agora, a importância dos fatores externos à instituição, além das questões de caráter financeiro. Tinto (1993), além de observar a integração do estudante ao contexto da instituição, acreditou ser importante acrescentar as características pessoais que contribuem para o comprometimento do estudante com seus objetivos e com a instituição, dando ênfase às experiências prévias e, também, ao contexto familiar.

Posteriormente, Tinto (1997) considerou o processo de aprendizagem como aspecto importante para se determinar a permanência ou o abandono do estudante no curso e na instituição. Nesse caso, a integração social e a acadêmica passaram a ter novo alcance, tornando-se item crucial no processo de aprendizagem, juntamente com técnicas pedagógicas e tecnologias disponibilizadas aos estudantes e docentes.

A teoria de desgaste do estudante proposta por Bean (1980) decorreu das contribuições do modelo proposto por Tinto (1975) e do pressuposto de que o estudante não tem mais um perfil tradicional, caracterizado como aquele indivíduo que, além de desenvolver suas tarefas acadêmicas, também desempenha um trabalho fora da instituição. Esse tipo de estudante apresenta características específicas, tais como a condição socioeconômica, sendo influenciado, também, pelo contexto em que está inserido e pelas diversas pressões de grupos sociais que o forçam a ingressar em um curso com o qual não se identifica totalmente, ou parcialmente, o que faz com que simplesmente desista do curso que iniciou e comece outro, ou mesmo abandone por completo a vida acadêmica.

Em se tratando da vida profissional, mudanças de local de trabalho podem ser determinantes na hora do estudante decidir permanecer ou abandonar o curso. Para Bean (1980), assim como o trabalhador prioriza o fator remuneração na hora de decidir sobre sua permanência no emprego, o estudante também considera seu desempenho acadêmico nas avaliações na hora de decidir sobre sua permanência no curso.

O modelo de Pascarella e Terenzini (1980) também foi baseado no modelo de integração do estudante proposto por Tinto (1975) e nas relações entre estudante, instituição e ambiente. Para os autores, a permanência ou não do estudante está relacionada com sua frequência e com a qualidade de seus contatos e informações fora da sala de aula. As demais características individuais influenciam o ambiente da instituição e as experiências sociais, acadêmicas e extracurriculares dos estudantes. Tais experiências, por sua vez, podem influenciar a quantidade de contato formal e todos os fatores que afetam os resultados educacionais. 
Também influenciado pelo modelo de Tinto (1975), Astin (1985) elaborou um modelo de envolvimento do estudante com enfoque no aspecto comportamental, e no modo como o indivíduo age como determinante no entendimento de seu envolvimento com a instituição.

Para Astin (1985), o envolvimento dos estudantes está relacionado à quantidade e à qualidade de energia física e psicológica investidas durante sua jornada. Esse envolvimento pode assumir muitas faces, como a absorção do estudo acadêmico, a participação em atividades extracurriculares e a interação com os docentes e outras pessoas da instituição. Nesse sentido, quanto maior for o envolvimento do estudante com a vida universitária, maiores serão as chances de sua permanência na instituição.

\subsection{Estudos empíricos sobre evasão universitária}

Por meio das teorias desenvolvidas por Spady (1970), Tinto (1975, 1993, 1997), Bean (1980), Pascarella e Terenzini (1980) e Astin (1985), estudos nacionais e internacionais sobre a temática da evasão foram desenvolvidos, principalmente no âmbito da graduação. Por meio desses estudos, foram encontrados diversos motivos que influenciam o estudante a abandonar ou não o curso em que está matriculado. No Quadro 1, evidenciam-se os principais.

Pode-se observar pela análise do Quadro 1, que os motivos contemplam tanto aspectos relacionados ao processo de adaptação do indivíduo ao ambiente de estudo (falta de relacionamento com os demais estudantes e com professores) como à estrutura e localização da instituição de ensino e ao próprio estudante (dificuldades nas disciplinas, vocação), além daqueles contingenciais (ingresso em outro curso) e envolvendo professores (pouca motivação). Adicionalmente, destaca-se que apenas os trabalhos de Canziani (2015), Golde (1998), Vergidis e Panagiotakopoulos (2002) e Zewotin et al. (2015) foram realizados no âmbito da pós-graduação (Quadro 1).

Canziani (2015) investigou as causas de evasão dos cursos de pós-graduação lato sensu da Universidade do Sul de Santa Catarina; Golde (1998) explorou o processo de evasão de três estudantes do curso de doutorado em Contabilidade na Universidade Oxford; Vergidis e Panagiotakopoulos (2002) traçaram as causas da evasão em um curso de pós-graduação em educação ofertado pela Universidade Aberta Helénica; e Zewotin et al. (2015) avaliaram o tempo que os estudantes levavam para concluir com sucesso ou abandonarem um programa de Mestrado da Universidade de KwaZulu-Natal, na costa oriental da África do Sul. Os demais trabalhos encontrados sobre o tema foram desenvolvidos no contexto da graduação. 


\begin{tabular}{|c|c|}
\hline Motivos & Referências \\
\hline Pressão familiar na escolha do curso & Gomes (1998) \\
\hline $\begin{array}{l}\text { Dificuldades de adaptação no novo } \\
\text { ambiente }\end{array}$ & Gomes (1998), Barbosa (2013), Rafael et al. (2015), Massi e Villani (2015) \\
\hline Falta de opção na escolha do curso & Gomes (1998), Sales (2013), Vitelli (2013), Rafael et al. (2015), Golde (1998) \\
\hline Falta de informação do curso & $\begin{array}{c}\text { Gomes (1998), Braga et al. (2003), Alves e Alves (2012), Castro (2012), Amaral } \\
\text { (2013), Slhessarenko et al. (2014), Camelo (2014), Canziani (2015), Gama } \\
\text { (2015), Massi e Villani (2015), Ambiel et al. (2016) }\end{array}$ \\
\hline $\begin{array}{l}\text { Dificuldades de conciliar o curso } \\
\text { com o trabalho }\end{array}$ & $\begin{array}{c}\text { Gomes (1998), Biazus (2004), Sales (2013), Amaral (2013), Villar (2014), } \\
\text { Canziani (2015), Rafael et al. (2015), Durso (2015), Gama (2015), Rocha (2015), } \\
\text { Ambiel et al. (2016), Vergidis e Panagiotakopoulos (2002) }\end{array}$ \\
\hline Variáveis socioeconômicas & $\begin{array}{l}\text { Gomes (1998), Braga, et al. (2003), Alves e Alves (2012), Amaral (2013), Vitelli } \\
\text { (2013), Nagai (2017), Durso (2015), Gomes (2015), Rocha (2015), Gama (2015), } \\
\text { Barbosa et al. (2016), Feitosa (2016), Bisinoto et al. (2016), Lima e Zago (2016), } \\
\text { Silva (2016) }\end{array}$ \\
\hline $\begin{array}{l}\text { Baixo desempenho acadêmico e } \\
\text { reprovações }\end{array}$ & $\begin{array}{l}\text { Braga et al. (2003), Sales (2013), Lima (2013), Vitelli (2013), Villar (2014), } \\
\text { Gomes (2015), Rocha (2015), Cornélio et al. (2016), Silva (2016), Díaz et al. } \\
\text { (2012), Gonzalez (2017) }\end{array}$ \\
\hline $\begin{array}{l}\text { Falta de metodologia de ensino pelos } \\
\text { professores }\end{array}$ & $\begin{array}{c}\text { Braga et al. (2003), Biazus (2004), Slhessarenko et al. (2014), Canziani (2015), } \\
\text { Durso (2015), Bisinoto et al. (2016) }\end{array}$ \\
\hline Processo de avaliação & $\begin{array}{c}\text { Braga et al. (2003), Slhessarenko et al. (2014), Villar (2014), Camelo (2014), } \\
\text { Canziani (2015), Durso (2015) }\end{array}$ \\
\hline Pouca motivação pelos professores & Biazus (2004), Slhessarenko et al. (2014), Villar (2014), Cornélio et al. (2016) \\
\hline $\begin{array}{l}\text { Falta de integração entre as } \\
\text { instituições }\end{array}$ & Biazus (2004), Villar (2014) \\
\hline Estrutura da instituição & $\begin{array}{l}\text { Palharini (2004), Andriola et al. (2006), Castro (2012), Barbosa (2013), } \\
\text { Slhessarenko et al. (2014), Camelo (2014), Gama (2015), Massi e Villani (2015), } \\
\text { Ambiel et al. (2016), Cornélio et al. (2016), Golde (1998), Díaz et al. (2012) }\end{array}$ \\
\hline $\begin{array}{l}\text { Falta de relacionamento com os } \\
\text { professores }\end{array}$ & Bardagi (2007), Castro (2012), Massi e Villani (2015) \\
\hline $\begin{array}{l}\text { Falta de relacionamento com os } \\
\text { demais estudantes }\end{array}$ & Bardagi (2007), Castro (2012), Massi e Villani (2015) \\
\hline $\begin{array}{l}\text { Distância entre a Instituição e a } \\
\text { Residência }\end{array}$ & Alves e Alves (2012), Sales (2013), Bisinoto et al. (2016) \\
\hline Ingresso em um novo curso & Amaral (2013), Slhessarenko et al., (2014), Silva (2016) \\
\hline Insatisfação com o curso & 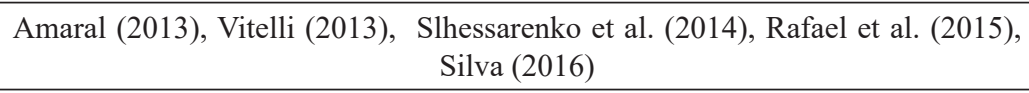 \\
\hline Incompatibilidade de horários & Canziani (2015), Rafael, et al. (2015) \\
\hline Dificuldades nas disciplinas & $\begin{array}{l}\text { Lima (2013), Vitelli (2013), Villar (2014), Gomes (2015), Rocha (2015), Barbosa } \\
\text { et al. (2016), Cornélio et al. (2016) }\end{array}$ \\
\hline Escolha precoce da profissão & Villar (2014), Gama (2015), Barbosa et al. (2016) \\
\hline $\begin{array}{l}\text { Dificuldades em conciliar os estudos } \\
\text { com a família e amigos }\end{array}$ & $\begin{array}{c}\text { Villar (2014), Canziani (2015), Massi e Villani (2015), Vergidis } \\
\text { e Panagiotakopoulos (2002) }\end{array}$ \\
\hline Turno que a instituição oferta o curso & Pereira et al. (2014) \\
\hline Desempenho passado insatisfatório & Pereira et al. (2014), Nagai (2017), Gomes (2015), Lima e Zago (2016) \\
\hline Vocação & Gama (2015), Barbosa et al. (2016) \\
\hline $\begin{array}{l}\text { Falta de tempo para dedicação aos } \\
\text { estudos }\end{array}$ & $\begin{array}{l}\text { Canziani (2015), Rafael et al. (2015), Durso (2015), Gama (2015), Rocha (2015), } \\
\text { Ambiel et al. (2016), Bisinoto et al. (2016), Vergidis e Panagiotakopoulos (2002) }\end{array}$ \\
\hline Fatores psicológicos & Golde (1998) \\
\hline
\end{tabular}

Quadro 1. Resumo dos motivos encontrados na literatura anterior

Fonte: elaborado pelos autores. 


\section{PROCEDIMENTOS METODOLÓGICOS}

Esta pesquisa, descritiva e explicativa, com abordagem quantitativa, classifica-se como de levantamento ou survey (Martins \& Theóphilo, 2016).

A população deste estudo engloba os estudantes de Mestrado e de Doutorado regularmente matriculados nos cursos de pós-graduação stricto sensu em Contabilidade no Brasil, cadastrados na Capes, no ano de 2018. De acordo com as informações disponibilizadas pela Capes por meio da plataforma Sucupira, e acessadas em 21 de março de 2018, 1.164 estudantes encontravam-se matriculados no Mestrado, 1006 na modalidade acadêmica e 158 na profissional, além de 369 no Doutorado.

Com os contatos dos estudantes, obtidos por meio das secretarias das instituições de ensino, foi encaminhado, em 03 de setembro de 2018, via e-mail, o instrumento de coleta de dados acompanhado do Termo de Consentimento Livre e Esclarecido (TCLE), aprovado pelo Comitê de Ética em Pesquisa da Universidade Federal de Minas Gerais, sob o número 85109518.4.0000.5149. Em 30 de outubro de 2018, encerrou-se a coleta de dados por meio de questionário. A amostra de pós-graduandos ficou composta pelos 619 estudantes que aceitaram ao convite e responderam o questionário até o seu encerramento, sendo: 447 mestrandos em Contabilidade (390 na modalidade acadêmica e 57 da profissional) e 172 doutorandos em Contabilidade.

O instrumento de coleta de dados, aplicado à população deste estudo, foi construído com base no trabalho de Durso (2015) e adaptado aos cursos de pós-graduação stricto sensu. O objetivo de Durso (2015) foi buscar evidências que permitissem caracterizar o processo de evasão dos estudantes do curso de Ciências Contábeis de uma Instituição de Ensino Superior (IES) pública brasileira. Foram necessárias adaptações em decorrência da diferença de contextos analisados: esta pesquisa foi realizada no âmbito da pós-graduação stricto sensu, enquanto aquela teve como foco a graduação e contemplou uma amostra de sujeitos já evadidos do curso.

Consequentemente, foram necessários ajustes de linguagem no instrumento utilizado por Durso (2015), de forma a tornar as assertivas voltadas à modalidade pesquisada e não ao sistema universitário de um modo geral. Assim, os motivos: "Dificuldade de adaptação ao sistema universitário"; "Falta de integração social com os demais alunos do curso de graduação"; "O curso apresentava pouca ênfase em disciplinas profissionalizantes"; e "A UFMG não disponibilizou o apoio necessário para que você pudesse se adaptar ao ritmo universitário", elencados no instrumento de Durso (2015), foram substituidos por, respectivamente: "Dificuldades de adaptação ao curso"; "Falta de integração social com os colegas do curso"; "O curso apresenta pouca ênfase em disciplinas de meu interesse" e "A instituição não disponibiliza o apoio necessário para que eu possa me adaptar ao ritmo do curso". Adicionalmente, foram acrescentados dois motivos que não foram investigados no trabalho de Durso (2015), a saber "Problemas de saúde" e "Solidão durante o curso".

A estrutura do questionário englobou questões demográficas e socioeconômicas dos respondentes; uma questão solicitando que o respondente marcasse o motivo que o levou a ingressar no curso em que estava matriculado e 22 motivos que, conforme a teoria, contribuiriam para a evasão dos estudantes. Essas sentenças representam questões relacionadas a problemas institucionais (adaptação à instituição, falta de informação por parte do curso), com os docentes (didática, falta de integração), externos (conciliar o curso com o trabalho, pressões familiares, pressões sociais) e do próprio estudante (falta de motivação, dificuldade para acompanhar o curso, problemas de saúde).

Para alcançar o objetivo deste estudo foram realizadas três etapas: (i) caracterização da amostra, (ii) motivos que levaram os pós-graduandos a ingressarem nos cursos de pós- graduação stricto sensu em Contabilidade e (iii) percepção sobre os motivos que contribuiriam para a evasão de estudantes dos cursos de pós-graduação stricto sensu em Contabilidade.

Na primeira etapa, foi feita uma descrição das características dos pós-graduandos que participaram da pesquisa, sendo analisada a frequência das respostas, em termos relativos e absolutos. Na segunda etapa, foram identificados os principais motivos que levaram os respondentes a ingressarem no curso em análise. Por meio da estatística descritiva, foi construído um ranking dessas motivações. Na terceira etapa, foi solicitado aos respondentes que atribuíssem notas de 1 a 10, elencando os motivos que mais contribuiriam (10) ou menos contribuiriam (1) para a evasão de estudantes dos cursos de pós-graduação stricto sensu em Contabilidade.

Foi criada uma hierarquia para categorizar as motivações como de baixa, de média e de alta propensão a evadir. Considerou-se o motivo como de baixo grau de propensão à evasão quando a média das notas atribuídas a ele ficou entre 1 (um) e 3 (três); como de médio grau de propensão à evasão quando a média das notas atribuídas a ele ficou acima de 3 (três) e abaixo de 6 (seis); e, como alto grau de propensão à evasão quando a média das notas atribuídas a ele ficou acima de 6 (seis). 
A divisão das notas atribuídas em baixo, médio e alto grau foi realizada a critério dos pesquisadores. Adicionalmente, foram efetuados testes $t$ de variância combinada para identificar a existência de diferenças estatisticamente significativas entre as médias das notas atribuídas por estudantes com diferentes perfis.

A amostra deste estudo compreendeu estudantes matriculados em todos os cursos de pós-graduação stricto sensu em Contabilidade do Brasil (ver Apêndice A).

Majoritariamente, os 390 pós-graduandos matriculados no Mestrado acadêmico são brancos, solteiros, do gênero feminino, estão na faixa etária entre 20 e 30 anos, residem na mesma cidade do curso, não são bolsistas, trabalham (preponderantemente na iniciativa privada), possuem renda familiar entre dois a cinco salários mínimos e participam da vida econômica familiar. Um perfil dos 57 pós-graduandos matriculados nos cursos de Mestrado profissional que participaram da pesquisa aponta para o gênero masculino, faixa etária entre 31 e 35 anos, residentes na cidade de localização do curso, não bolsistas, trabalhando na iniciativa privada, com renda familiar acima de dez salários mínimos e participantes da vida econômica familiar.

Em relação aos 172 doutorandos que participaram da pesquisa, predominantemente, são do gênero feminino, estão na faixa etária entre 26 e 30 anos, residem na mesma cidade do curso, não são bolsistas, trabalham (especialmente na iniciativa pública), têm renda familiar entre cinco e dez salários mínimos e participam da vida econômica familiar.

\section{RESULTADOS}

\subsection{Motivos para ingressar nos cursos de pós- graduação stricto sensu em Contabilidade}

Além de informações sobre o perfil dos estudantes, os pós-graduandos também foram questionados sobre o principal motivo que os levaram a ingressarem nos cursos stricto sensu em Contabilidade. Para Lapini (2012), o objetivo do curso stricto sensu na modalidade acadêmica é habilitar o estudante para o exercício da carreira docente. De acordo com o ranking do Gráfico 1, para os estudantes dos cursos de Mestrado Acadêmico, a aptidão para a área acadêmica foi o motivo que levou 38\% deles a ingressarem no curso. Seguido do aumento da remuneração, assinalado por $11 \%$ dos estudantes. Também, 10\% ingressaram para se aprofundarem na área e 7\% para alcançar maior empregabilidade. Percebe-se, ainda, que a falta de opção, o prestígio do curso e a maior produtividade foram motivos de ingresso elencados por apenas $1 \%$ dos estudantes, cada um deles. Nenhum estudante identificou como motivo a gratuidade do curso, independente de estarem matriculados em instituições públicas ou privadas.

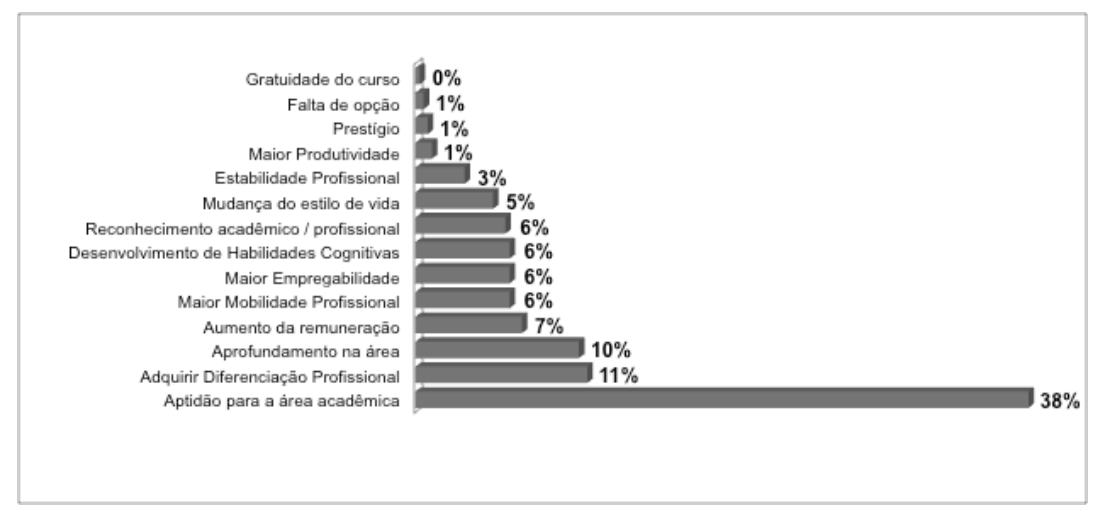

Gráfico 1. Motivos que levaram os estudantes a ingressarem no curso de Mestrado Acadêmico

Fonte: elaborado pelos autores.

De acordo com a Capes (2014), o Mestrado Profissional agrega um nível maior de competitividade e de produtividade a empresas públicas ou privadas, contribuindo com o setor produtivo nacional. Esta modalidade de Mestrado é regulamentada pelas portarias n 389 do MEC e n ${ }^{\circ} 131$ da Capes de 2017. Nela, 25\% dos estudantes alegaram ter ingressado no curso para adquirir diferenciação profissional, o que já era esperado, visto que este é o principal objetivo dos cursos desta modalidade. Por outro lado, 19\% dos estudantes ingressaram pela aptidão à área acadêmica, 19\% pelo aprofundamento da área, 14\% pela maior empregabilidade e $9 \%$ pela maior mobilidade profissional. Nenhum respondente elencou como motivo a gratuidade do curso, maior produtividade, desenvolvimento de habilidades cognitivas, prestígio ou falta de opção. Os demais motivos podem ser verificados no ranking apresentado no Gráfico 2. 


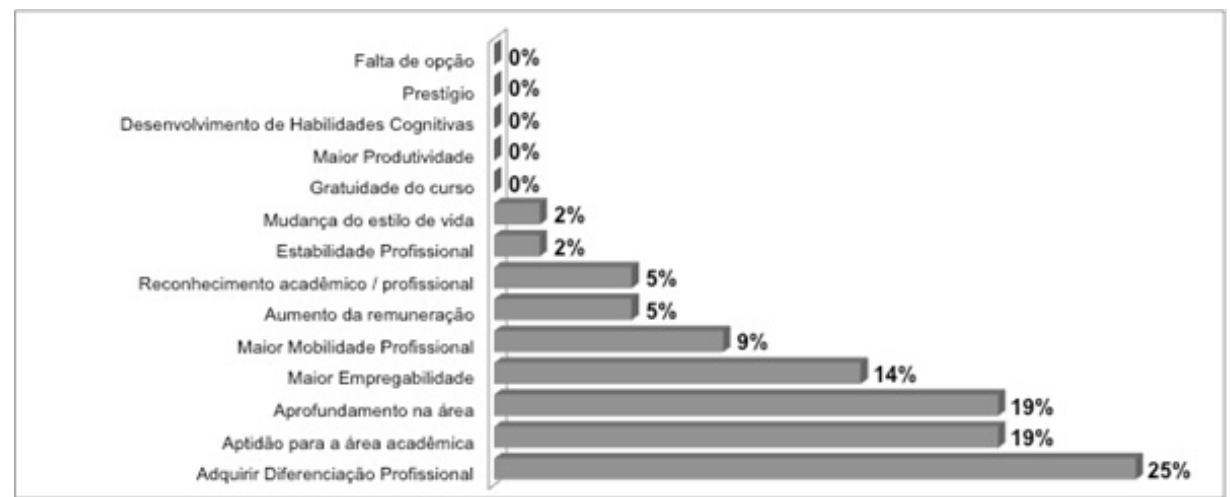

Gráfico 2. Motivos que levaram os estudantes a ingressarem no curso de Mestrado Profissional

Fonte: elaborado pelos autores.

Ainda de acordo com a Capes (2014), a formação de docentes, o estímulo e o desenvolvimento de pesquisa acadêmica por meio da preparação adequada de pesquisadores são os dois objetivos práticos do Mestrado Acadêmico e do Doutorado. Conforme o ranking apresentado no Gráfico 3, a aptidão para a área acadêmica foi o motivo que levou $44 \%$ dos estudantes matriculados nos cursos de Doutorado a ingressarem neles, mesmo que a aptidão para a área acadêmica, conforme os objetivos da Capes (2014), já seja habilitada aos estudantes com título de mestre. Por outro lado, maior produtividade e aprofundamento na área, que também são objetivos fundamentais dos cursos de Doutorado, foram motivos de ingresso para 2\% e 9\% dos estudantes, respectivamente. O aumento da remuneração foi o motivo de ingresso indicado por $12 \%$ dos estudantes.

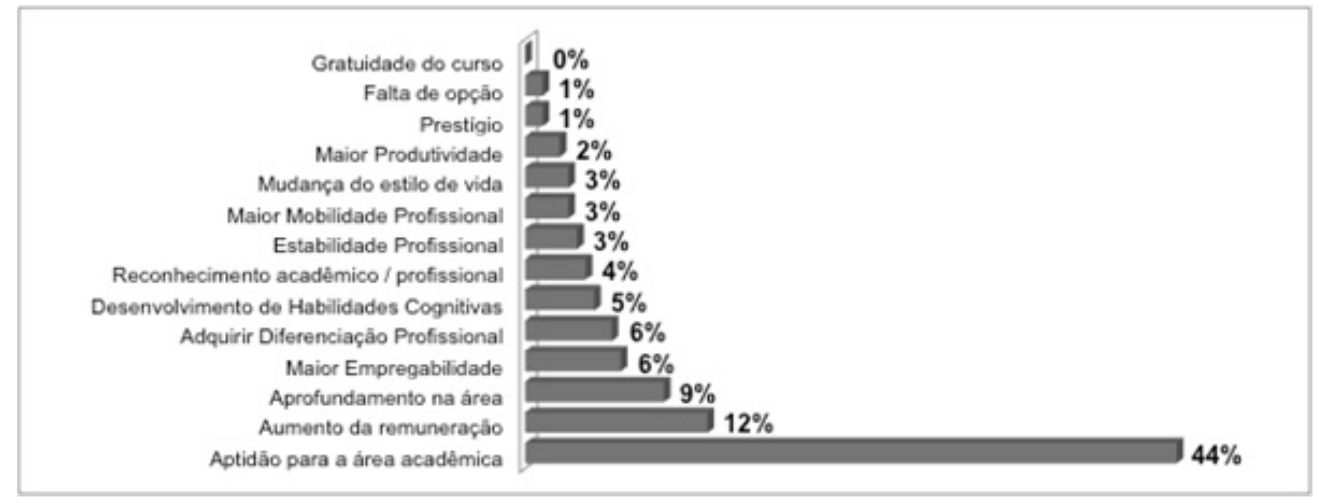

Gráfico 3. Motivos que levaram os estudantes a ingressarem no curso de Doutorado Fonte: elaborado pelos autores.

Em síntese, conforme já esperado, a aptidão para a área acadêmica foi o motivo principal elencado pelos estudantes de Mestrado e de Doutorado na modalidade acadêmica, tendo em vista que o objetivo de tal modalidade é justamente habilitar o estudante para o exercício da carreira docente, sendo imprescindível para isso aptdão para a área. Na modalidade profissional, o destaque se deu no item adquirir diferenciação profissional, o que também era um resultado esperado para esta modalidade. Resultado interessante foi observado no item aptidão para a área acadêmica, elencado por $19 \%$ dos estudantes, mesmo eles tendo escolhido a modalidade de ensino profissional em detrimento da acadêmica, que talvez fosse a mais adequada nesses casos.

\subsection{Motivos que contribuiriam para a evasão dos cursos de pós-graduação stricto sensu em Contabilidade}

Por meio da média das notas atribuídas pelos estudantes matriculados nos cursos de pós-graduação stricto sensu em Contabilidade na terceira parte do instrumento de pesquisa, foi possível identificar os motivos que mais contribuiriam para a evasão. O motivo foi considerado como de baixo grau de propensão à evasão quando a média das notas atribuídas ficou entre 1 (um) e 3 (três); como de médio grau de propensão à evasão quando a média das notas atribuídas ficou acima de 3 (três) e abaixo de 6 (seis); e, como de alto grau de propensão à evasão quando a média das notas atribuídas ficou acima de 6 (seis). 
Para os estudantes matriculados nos cursos de Mestrado em Contabilidade (modalidades acadêmica e profissional), as dificuldades para acompanhar o curso devido ao tempo necessário para os estudos foi indicado como o motivo que mais levaria à evasão (média =6,266), representando um alto grau de propensão. A dificuldade para conciliar as atividades acadêmicas com as atividades profissionais (média $=5,884$ ) e as dificuldades para acompanhar o curso devido à falta de recursos financeiros (média $=5,091)$ representaram motivos de grau médio. Por outro lado, o ingresso no curso pela aprovação no processo de seleção mesmo não sendo a escolha do estudante (média $=2,327$ ) e a perda de prestígio da carreira contábil (média $=2,564$ ) foram os motivos com menores médias, representando motivos de grau baixo, conforme apresentado na Tabela 1.

Tabela 1. Notas atribuídas pelos estudantes do Mestrado

\begin{tabular}{|c|c|c|c|}
\hline $\mathbf{N}^{\circ}$ & Motivo & Média & Grau de propensão \\
\hline 2 & $\begin{array}{l}\text { Dificuldades para acompanhar o curso devido ao tempo necessário para } \\
\text { os estudos }\end{array}$ & 6,2662192 & Alto \\
\hline 1 & Dificuldades para acompanhar o conteúdo ministrado no curso & 4,57718121 & Médio \\
\hline 3 & $\begin{array}{l}\text { Dificuldades para acompanhar o curso devido à falta de recursos } \\
\text { financeiros }\end{array}$ & 5,0917226 & Médio \\
\hline 4 & Desempenho acadêmico insatisfatório & 4,0917226 & Médio \\
\hline 5 & Deficiência didática dos professores & 4,20581655 & Médio \\
\hline 6 & Falta de motivação em continuar no curso & 4,88590604 & Médio \\
\hline 7 & Dificuldades de adaptação ao curso & 4,62863535 & Médio \\
\hline 10 & O curso apresenta pouca ênfase em disciplinas de meu interesse & 4,08277405 & Médio \\
\hline 11 & Deficiência na infraestrutura da instituição & 3,08501119 & Médio \\
\hline 13 & O curso não era o que eu imaginava & 4,27069351 & Médio \\
\hline 15 & Falta de receptividade dos professores do curso & 3,77628635 & Médio \\
\hline 16 & $\begin{array}{l}\text { A instituição não disponibiliza o apoio necessário para que eu possa me } \\
\text { adaptar ao ritmo do curso }\end{array}$ & 4,05369128 & Médio \\
\hline 17 & A profissão não permite que eu alcance o retorno financeiro que desejo & 3,32885906 & Médio \\
\hline 19 & $\begin{array}{l}\text { Dificuldades para conciliar as atividades acadêmicas com as atividades } \\
\text { profissionais }\end{array}$ & 5,8836689 & Médio \\
\hline 20 & $\begin{array}{l}\text { Não foram disponibilizadas informações necessárias para que eu } \\
\text { entendesse melhor sobre o curso que ingressei }\end{array}$ & 3,4049217 & Médio \\
\hline 21 & Problemas de saúde & 4,27293065 & Médio \\
\hline 22 & Solidão durante o curso & 4,15212528 & Médio \\
\hline 8 & Falta de integração social com os estudantes do curso & 2,95749441 & Baixo \\
\hline 9 & O currículo do curso é desatualizado & 2,98657718 & Baixo \\
\hline 12 & Perda de prestígio da carreira contábil & 2,56375839 & Baixo \\
\hline 14 & Percebi que não me sinto bem na profissão & 3,00223714 & Baixo \\
\hline 18 & $\begin{array}{l}\text { Entrei no curso porque passei no processo de seleção, mas na verdade } \\
\text { essa não foi a minha escolha }\end{array}$ & 2,32662192 & Baixo \\
\hline
\end{tabular}

Fonte: elaborada pelos autores.

Os estudantes matriculados nos cursos de Doutorado em Contabilidade não indicaram motivos que representassem uma contribuição de alto grau na propensão para a evasão (ver Tabela 2). Quanto aos motivos de grau médio, assim como verificado em relação aos estudantes dos cursos de Mestrado, apresentaram pontuações superiores as dificuldades para conciliar as atividades acadêmicas com as atividades profissionais $($ média $=5,383$ ) e as dificuldades para acompanhar o curso devido ao tempo necessário para os estudos (média = 5,198). A perda de prestígio da carreira contábil (média $=2,419)$ e a percepção de não se sentir bem na profissão $($ média $=2,593)$ foram motivos avaliados pelos estudantes de Doutorado como de grau baixo. 
Tabela 2. Notas atribuídas pelos estudantes do Doutorado

\begin{tabular}{|c|c|c|c|}
\hline $\mathbf{N}^{\circ}$ & Motivos & Média & Grau de propensão \\
\hline 1 & Dificuldades para acompanhar o conteúdo ministrado no curso & 3,8313953 & Médio \\
\hline 2 & $\begin{array}{l}\text { Dificuldades para acompanhar o curso devido ao tempo necessário para } \\
\text { os estudos }\end{array}$ & 5,1976744 & Médio \\
\hline 3 & $\begin{array}{l}\text { Dificuldades para acompanhar o curso devido à falta de recursos } \\
\text { financeiros }\end{array}$ & 4,3604651 & Médio \\
\hline 4 & Desempenho acadêmico insatisfatório & 3,4767442 & Médio \\
\hline 5 & Deficiência didática dos professores & 4,2151163 & Médio \\
\hline 6 & Falta de motivação em continuar no curso & 4,5755814 & Médio \\
\hline 7 & Dificuldades de adaptação ao curso & 4,0290698 & Médio \\
\hline 8 & Falta de integração social com os estudantes do curso & 3,0116279 & Médio \\
\hline 9 & O currículo do curso é desatualizado & 3,0290698 & Médio \\
\hline 10 & O curso apresenta pouca ênfase em disciplinas de meu interesse & 4,0988372 & Médio \\
\hline 11 & Deficiência na infraestrutura da instituição & 3,2325581 & Médio \\
\hline 13 & O curso não era o que eu imaginava & 3,627907 & Médio \\
\hline 15 & Falta de receptividade dos professores do curso & 3,7790698 & Médio \\
\hline 16 & $\begin{array}{l}\text { A instituição não disponibiliza o apoio necessário para que eu possa me } \\
\text { adaptar ao ritmo do curso }\end{array}$ & 3,8081395 & Médio \\
\hline 19 & $\begin{array}{l}\text { Dificuldades para conciliar as atividades acadêmicas com as atividades } \\
\text { profissionais }\end{array}$ & 5,3837209 & Médio \\
\hline 21 & Problemas de saúde & 4,6511628 & Médio \\
\hline 22 & Solidão durante o curso & 4,0465116 & Médio \\
\hline 14 & Percebi que não me sinto bem na profissão & 2,5930233 & Baixo \\
\hline 12 & Perda de prestígio da carreira contábil & 2,4186047 & Baixo \\
\hline 17 & A profissão não permite que eu alcance o retorno financeiro que desejo & 2,8953488 & Baixo \\
\hline 18 & $\begin{array}{l}\text { Entrei no curso porque passei no processo de seleção, mas na verdade } \\
\text { essa não foi a minha escolha }\end{array}$ & 2,6662791 & Baixo \\
\hline 20 & $\begin{array}{l}\text { Não foram disponibilizadas informações necessárias para que eu } \\
\text { entendesse melhor sobre o curso que ingressei }\end{array}$ & 2,9011628 & Baixo \\
\hline
\end{tabular}

Fonte: elaborada pelos autores.

Em suma, foi possível observar que a maior parte dos estudantes de Mestrado e de Doutorado considerou que as dificuldades para acompanhar o conteúdo ministrado no curso (motivo 1), as dificuldades para acompanhar o curso devido à falta de recursos financeiros (motivo 3), as dificuldades de adaptação ao curso (motivo 7) e a falta de informações necessárias (motivo 20) são motivos que contribuiriam para a evasão de estudantes dos cursos stricto sensu em Contabilidade em um grau baixo (média entre 2,326 e 5,092). Os testes de diferença médias revelaram que as médias das notas atribuídas pelos mestrandos e pelos doutorandos foram estatisticamente diferentes ( $\mathrm{p}$-valor $<0,05$ ), apesar de apresentarem o mesmo grau.

Quanto à deficiência didática dos professores (motivo 5), à falta de motivação em continuar no curso (motivo 6), à falta de integração social com os estudantes do curso (motivo 8), ao currículo do curso desatualizado (motivo 9), à pouca ênfase em disciplinas de interesse do estudante (motivo 10), à deficiência na infraestrutura da instituição (motivo 11), à perda de prestígio da carreira contábil (motivo 12), a não se sentir bem na profissão (motivo 14), à falta de receptividade dos professores do curso (motivo 15), à falta de apoio necessário por parte da instituição para que o estudante possa se adaptar ao ritmo do curso (motivo 16), à profissão não permitir que o estudante alcance o retorno financeiro desejado (motivo 17), à ingressar no curso porque passou no processo seletivo mesmo não sendo a sua escolha (motivo 18), a problemas de saúde (motivo 21), à solidão durante o curso (motivo 22) e ao curso não ser o que o estudante imaginava (motivo 13), foram considerados pela maior parte dos estudantes de Mestrado e de Doutorado como motivos de grau baixo (média entre 2,418 e 4,885) na contribuição para a evasão de estudantes dos cursos stricto sensu em Contabilidade. No entanto, as médias das notas atribuídas pelos mestrandos e as atribuídas pelos doutorandos para esses motivos foram consideradas estatisticamente iguais (p-valor $>0,05)$. 
As dificuldades para acompanhar o curso devido ao tempo necessário para os estudos (motivo 2) e o desempenho acadêmico insatisfatório (motivo 4) foram considerados motivos de grau alto (média entre 3,476 e 6,267) que contribuiriam para a evasão de estudantes dos cursos de pós-graduação stricto sensu em Contabilidade, para a maior parte dos estudantes de Mestrado e de Doutorado. Nesse caso, as médias das notas atribuídas pelos mestrandos e pelos doutorandos foram consideradas estatisticamente diferentes ( $\mathrm{p}$-valor $=0,0001$ ).

Finalmente, as dificuldades para conciliar as atividades acadêmicas com as atividades profissionais (motivo 19) foi um motivo entendido como de grau alto (média entre 5,383 e 5,883), que contribuiria para a evasão de estudantes dos cursos stricto sensu em Contabilidade, tanto por mestrandos quanto por doutorandos, com média das notas consideradas estatisticamente iguais ( $\mathrm{p}$-valor $=0,0935)$.

Os motivos que mais contribuiriam para a evasão de estudantes foram analisados, também, levando em consideração outras características do perfil dos discentes, além da modalidade do curso. Desta forma, foram consideradas para a análise as seguintes características: o gênero do estudante, a idade, o fato de ele ser bolsista ou não, se trabalha ou não, a renda e o fato de ele residir ou não na cidade de localização do curso (ver Apêndices $\mathrm{B}$ e C).

Para as estudantes do gênero feminino, as dificuldades para acompanhar o curso devido ao tempo necessário para os estudos foi indicado como o motivo que mais contribuiria para a evasão (motivo 2 , média $=$ 6,1351), representando um alto grau de propensão. Em relação aos discentes do gênero masculino, não houve indicação de motivos que representassem uma contribuição de alto grau na propensão à evasão. Dentre as motivações elencadas como de baixo grau, as mulheres indicaram a perda de prestígio da carreira contábil (média $=2,5616$ ) e a possibilidade de entrada no curso porque passou no processo de seleção, mas na verdade essa não era a escolha (média $=2,4024)$. Os homens indicaram estes mesmos motivos como de baixo grau, além de elencarem outros três: a falta de integração social com os estudantes do curso (motivo 8, média $=2,7624$ ), o fato de não se sentirem bem na profissão (motivo 14 , média $=2,4929$ ) e o fato de a profissão não permitir que o estudante alcance o retorno financeiro desejado (motivo 17, média $=2,9965$ ). As médias das notas atribuídas pelas estudantes do gênero feminino e masculino foram consideradas estatisticamente diferentes apenas em relação ao motivo 14 (p-valor $=0,0008)$.

Em relação à idade, para os estudantes mais velhos (idade superior à mediana de 31 anos), as dificuldades para acompanhar o curso devido ao tempo necessário para os estudos foi indicado como o motivo que mais contribuiria para a evasão (motivo 2 , média $=6,2491$ ). Os estudantes mais jovens (idade inferior a 31 anos) não indicaram motivos que representassem uma contribuição de alto grau na propensão para a evasão. Quanto aos motivos elencados como de baixo grau na propensão para a evasão, os estudantes mais jovens indicaram os seguintes: a falta de integração social com os estudantes do curso (motivo 8, média =2,9942), o fato de o currículo do curso ser desatualizado (motivo 9, média =2,8830), a perda de prestígio da carreira contábil (motivo 12, média $=2,5058$ ) e a possibilidade de entrada no curso porque passou no processo de seleção, mas na verdade essa não era a escolha (motivo 18 , média $=2,3567$ ).

Já os estudantes mais velhos indicaram como motivos de baixo grau na propensão para a evasão: motivos 8 (média $=2,9458), 12$ (média =2,5451) e 18 (média =2,3141), em consonância com as percepções dos discentes mais jovens, além de indicarem o fato de não se sentirem bem na profissão (motivo 14, média $=2,6715$ ) e de a profissão não permitir que o estudante alcance o retorno financeiro desejado (motivo 17 , média $=2,9711$ ). As médias das notas atribuídas pelos estudantes mais velhos e mais jovens foram consideradas estatisticamente diferentes apenas em relação aos motivos 2 e 17 (p-valores $=0,0361$ e 0,0413, respectivamente).

Os estudantes bolsistas não indicaram motivos que representassem uma contribuição de alto grau na propensão para a evasão. Já para os não bolsistas, as dificuldades para acompanhar o curso devido ao tempo necessário para os estudos (motivo 2, média $=6,4237$ ) e as dificuldades para conciliar as atividades acadêmicas com as atividades profissionais (motivo 19 , média $=6,4289$ ) foram indicados como os motivos que mais contribuiriam para a evasão, representando um alto grau de propensão. Quanto aos motivos elencados como de baixo grau na propensão à evasão, os estudantes bolsistas indicaram: o fato de o currículo do curso ser desatualizado (motivo 9, média $=3,000$ ), a perda de prestígio da carreira contábil (motivo 12, média $=2,4937$ ) e a possibilidade de entrada no curso porque passou no processo de seleção, mas na verdade essa não era a escolha (motivo 18, média $=2,5732$ ).

Os estudantes não bolsistas elencaram, além das motivações já destacadas pelos bolsistas (9, 12 e 18), outros dois motivos adicionais como de baixo grau na propensão para a evasão: a falta de integração social com os estudantes do curso (motivo 8 , média $=2,8684$ ) e o fato de não se sentirem bem na profissão (motivo 14 , média $=2,6605$ ). As médias das notas atribuídas pelos estudantes bolsistas e não bolsistas foram consideradas estatisticamente diferentes apenas em relação aos motivos 2, 14 e 19 (p-valores = 0,0000, 0,0156 e 0,0000, respectivamente). 
Os discentes que trabalham, de forma equivalente ao indicado pelos estudantes não bolsistas, elencaram as dificuldades para acompanhar o curso devido ao tempo necessário para os estudos (motivo 2, média $=6,3366$ ) e as dificuldades para conciliar as atividades acadêmicas com as atividades profissionais (motivo 19, média $=6,4307$ ) como os motivos que mais contribuiriam para a evasão, representando um alto grau de propensão. Os alunos que não trabalham não indicaram motivos que representassem uma contribuição de alto grau na propensão para a evasão. Dentre os motivos elencados como de baixo grau na propensão à evasão, os estudantes que trabalham indicaram: a falta de integração social com os estudantes do curso (motivo 8, média $=2,7847$ ), o fato de o currículo do curso ser desatualizado (motivo $9=2,9455$ ), a deficiência na infraestrutura da instituição (motivo 11, média = 2,9307 ), a perda de prestígio da carreira contábil (motivo 12, média $=2,4381$ ), o fato de não se sentirem bem na profissão (motivo 14, média = 2,6361) e a possibilidade de entrada no curso porque passou no processo de seleção, mas na verdade essa não era a escolha (motivo 18 , média $=2,5256$ ).

Os estudantes que não trabalham elencaram os motivos 12 e 18 como de baixo grau na propensão para a evasão. As médias das notas atribuídas pelos estudantes que trabalham e pelos discentes que não trabalham foram consideradas estatisticamente diferentes apenas em relação aos motivos 2, 8, 11, 14 e 19 (p-valores =0,0467, 0,0451, 0,0307, 0,0107 e 0,0000, respectivamente).

Os estudantes com maior renda (superior a cinco salários mínimos), de modo equivalente aos discentes que trabalham e aos estudantes não bolsistas, talvez por se tratar de um grupo único de estudantes, indicaram as dificuldades para acompanhar o curso devido ao tempo necessário para os estudos (motivo 2, média $=6,0455)$ e as dificuldades para conciliar as atividades acadêmicas com as atividades profissionais (motivo 19, média $=6,0126$ ) como os que mais contribuiriam para a evasão, representando um alto grau de propensão. Os discentes com menor renda (até cinco salários mínimos) elencaram a falta de recursos financeiros (motivo 3, média =6,0807) como o motivo que mais contribuiria para a evasão.

Em relação aos motivos elencados como de baixo grau na propensão para a evasão, os discentes com maior renda indicaram os seguintes: a falta de integração social com os estudantes do curso (motivo 8 , média $=2,6970$ ), o fato de o currículo do curso ser desatualizado (motivo 9 , média $=2,9520$ ), a perda de prestígio da carreira contábil (motivo 12, média $=2,3813$ ), o fato de não se sentirem bem na profissão (motivo 14 , média $=$ 2,5682 ) e a possibilidade de entrada no curso porque passou no processo de seleção, mas na verdade essa não era a escolha (motivo 18, média = 2,2096). Os estudantes com menor renda elencaram os motivos 12 e 18 como de baixo grau na propensão para a evasão. As médias das notas atribuídas pelos estudantes com maior renda e pelos discentes com menor renda foram consideradas estatisticamente diferentes apenas em relação aos motivos 3,8 e 14 (p-valores $=0,0000,0,0082$ e 0,0017, respectivamente).

Por fim, a última característica analisada foi o fato de o estudante residir na cidade de localização do curso ou fora dela. Os discentes que residem fora da cidade de localização do curso, indicaram as dificuldades para acompanhar o curso devido ao tempo necessário para os estudos (motivo 2, média $=6,1604$ ) como o motivo que mais contribuiria para a evasão, representando um alto grau de propensão. Os alunos que residem na cidade de localização do curso não indicaram motivos que representassem uma contribuição de alto grau na propensão para a evasão. Quanto aos motivos elencados como de baixo grau na propensão para a evasão, os discentes que residem fora da cidade do curso indicaram: o fato de o currículo do curso ser desatualizado (motivo 9, média $=2,8585$ ), a perda de prestígio da carreira contábil (motivo 12 , média $=2,6745$ ) e a possibilidade de entrada no curso porque passou no processo de seleção, mas na verdade essa não era a escolha (motivo 18, média $=2,4575$ ).

Os estudantes que residem na cidade de localização do curso, além das motivações 12 e 18, já elencadas pelo grupo de discentes que reside fora dela, adicionaram os seguintes motivos como de baixo grau na propensão para a evasão: a falta de integração social com os estudantes do curso (motivo 8, média $=2,9017$ ) e o fato de não se sentirem bem na profissão (motivo 14 , média $=2,8133$ ). As médias das notas atribuídas pelos estudantes que residem na cidade de localização do curso e pelos discentes que residem fora dela foram consideradas estatisticamente diferentes apenas em relação ao motivo 2 ( $p$-valor $=0,0388$ ).

Em síntese, foram encontrados indícios de que pós-graduandos do gênero feminino, estudantes mais velhos, alunos não bolsistas, discentes que trabalham, com maior renda e aqueles que residem fora da cidade de localização do curso, veem as dificuldades para acompanhar o curso devido ao tempo necessário para os estudos como um motivo que contribuiria fortemente para a evasão. Estes grupos de indivíduos parecerem ter que conciliar outras atividades relevantes com a pós-graduação, além de gastarem um período com deslocamento, de modo que considerariam abandonar o curso caso o tempo se tornasse escasso para se dedicarem adequadamente ao Mestrado ou ao Doutorado. 


\section{CONSIDERAÇÕES FINAIS}

O objetivo deste estudo foi identificar a percepção de pós-graduandos sobre os motivos que contribuiriam para a evasão de estudantes dos cursos de pós-graduação stricto sensu em Contabilidade. Adicionalmente, pretendeuse verificar os motivos que os levaram a ingressarem nos cursos em questão. Foram avaliadas as percepções de 447 discentes matriculados nos cursos de Mestrado em Contabilidade (390 da modalidade acadêmica e 57 da profissional) e de 172 matriculados nos cursos de Doutorado em Contabilidade, mediante o preenchimento de um questionário.

Em relação aos motivos que contribuiriam para a evasão de estudantes dos cursos de pós-graduação stricto sensu em Contabilidade, aqueles que mais se destacaram, culminando em um alto grau de contrubuição para o abandono do curso, foram as dificuldades para acompanhar o curso devido ao tempo necessário para os estudos e as dificuldades para conciliar as atividades acadêmicas com as atividades profissionais. Este resultado confirma as teorias de Spady (1970), Tinto (1975) e Bean (1980) e coadunam os achados de Gomes (1998), Biazus (2004), Sales (2013), Amaral (2013), Villar (2014), Canziani (2015), Rafael et al. (2015), Durso (2015), Gama (2015), Rocha (2015), Ambiel et al. (2016), Vergidis e Panagiotakopoulos (2002) e Gonzalez (2017), evidenciando que são motivos que podem ser determinantes para a evasão dos estudantes.

Analisando separadamente os diferentes perfis de discentes, nota-se que o motivo - as dificuldades para acompanhar o curso devido ao tempo necessário para os estudos - indicado como forte contribuinte para a evasão, foi reforçado, especialmente, por estudantes matriculados nos cursos de Mestrado em Contabilidade, por mulheres, por estudantes mais velhos, por alunos não bolsistas, por discentes que trabalham, por estudantes com maior renda e por aqueles que residem fora da cidade de localização do curso.

As evidências empíricas demonstraram que, em relação aos motivos que levaram os estudantes a ingressarem na pós-graduação stricto sensu em Contabilidade, predominou a aptidão para a área acadêmica, entre os discentes do Mestrado Acadêmico. Tal resultado era esperado, tendo em vista que o objetivo principal desta modalidade de curso é justamente habilitar o estudante para o exercício da carreira docente.

Em relação aos discentes do Mestrado Profissional, o motivo mais elencado foi adquirir diferenciação profissional, o que também já era esperado. Um achado interessante é que, mesmo ingressando em um Mestrado na modalidade profissional, $19 \%$ dos estudantes relataram que o principal motivo para o ingresso no curso foi a aptidão à área acadêmica, o que suscita dúvidas em relação à modalidade escolhida. Talvez, para estes indivíduos, um Mestrado Acadêmico seria o mais apropriado.

No que tange aos estudantes matriculados nos cursos de Doutorado, a maioria deles indicou como motivo para ingresso no curso a aptidão à area acadêmica, de forma similar ao elencado pelos respondentes do Mestrado Acadêmico. Percebe-se, desse modo, que tal aptidão favorece o interesse pela continuidade dos estudos, mesmo a formação docente já sendo possível apenas com o curso de Mestrado. Talvez o interesse por tal continuidade se dê também em decorrência das vagas oferecidas pelas Instituições de Ensino Superior (IES) para o preenchimento de seu quadro docente, que quase sempre exigem a titulação de Doutor ou conferem pontuações superiores a quem possua o título em questão.

Tais achados reforçam a necessidade de discussões sobre o tema no âmbito das IES, com o intuito de apoiar os estudantes ao longo da realização de suas atividades acadêmicas. Ao reconhecerem possíveis dificuldades relatadas pelos discentes, os membros das instituições de ensino têm a oportunidade de buscar alternativas para auxiliá-los a lidar com situações de desconforto na universidade, incluindo a discussão de técnicas que permitam o melhor planejamento do tempo dedicado às atividades acadêmicas e evitem, por exemplo, o processo de procrastinação.

Os estudantes, contando com o auxílio dos docentes, das instituições de ensino e dos próprios colegas, poderão realizar um planejamento mais adequado do tempo, organizando os dias para que a realização das atividades seja mais eficiente. Tal planejamento, além do apoio dos diversos atores envolvidos no processo de ensino-aprendizagem, pode fazer com que o estudante se sinta assistido e melhore seu desempenho acadêmico, culminando, em última instâcia, na possibilidade de minimizar a evasão.

Como limitações deste estudo, deve-se ressaltar o fato de que os resultados encontrados não extrapolam a amostra pesquisada. Além disso, destacam-se as limitações do próprio instrumento de coleta de dados, que por conter questões fechadas, impede que motivos diferentes sejam elencados pelos pesquisados. Para estudos futuros, sugere-se a realização de uma pesquisa especificamente com os estudantes evadidos, de forma que seja possível investigar os motivos que efetivamente contribuíram para o processo de evasão. Sugere-se, ainda, incluir nos estudos professores e coordenadores de cursos de pós-graduação stricto sensu ou de outras modalidades para verificar a visão dos docentes sobre esse fenômeno. 


\section{REFERÊNCIAS}

Adachi, A. A. C. T. (2009). Evasão e evadidos nos cursos de graduação da Universidade Federal de Minas Gerais. (Dissertação de Mestrado). Belo Horizonte: UFMG / FAE.

Alves, V. V. F., \& Alves, T. W. (2012). Fatores determinantes da evasão universitária: uma análise com alunos da Unisinos. Contextus, 10(2).

Amaral, J. B. D. (2013). Evasão discente no ensino superior: estudo de caso no Instituto Federal de Educação, Ciência e Tecnologia do Ceará (Campus Sobral). 2013. 48 f (Tese de Doutorado) do programa de PósGraduação em Superintendência de Recursos Humanos, Universidade Federal do Ceará, Fortaleza).

Ambiel, R. A. (2015). Construção da Escala de Motivos para Evasão do Ensino Superior. Avaliação Psicológica, $14(1), 41-52$.

Ambiel, R. A., Carvalho, L. D. F., Moreira, T. D. C., \& Bacan, A. R. (2016). Funcionamento diferencial dos itens na Escala de Motivos para Evasão do Ensino Superior (M-ES). Psico, 47(1), 68-76. DOI: 10.15448/19808623.2016.1.21765

Andriola, W. B., Andriola, C. G., \& Moura, C. P. (2006). Opiniões de docentes e de coordenadores acerca do fenômeno da evasão discente dos cursos de graduação da Universidade Federal do Ceará (UFC). Ensaio: aval. pol.públ. Educ, 14(52). DOI: https://doi.org/10.1590/S0104-40362006000300006

Astin, A. W. (1985). Student involvement: A developmental theory for higher education. Journal of college student personnel, 25(4), 297-308.

Barbosa, C. L. D. (2013). Preditores de evasão em diferentes ambientes acadêmicos. (Dissertação de Mestrado). Programa de Pós-graduação em Psicologia. Universidade Federal da Bahia.

Barbosa, E. T., Nascimento Filho, R., Azevedo Filho, A. C., \& Biavatti, V. T. (2016) Fatores determinantes da evasão no curso de Ciências Contábeis de uma Instituição Pública de Ensino Superior. In: Anais do XIII Congresso USP de Contabilidade.

Bardagi, M. P. (2007). Evasão e comportamento vocacional de universitários: estudos sobre o desenvolvimento de carreira na Graduação (Tese de Doutorado), Universidade Federal do Rio Grande do Sul).

Bean, J. P. (1980). Dropouts and turnover: The synthesis and test of a causal model of student attrition. Research in higher education, 12(2), 155-187. DOI: https://doi.org/10.1007/BF00976194

Braga, M. M., Peixoto, M. D. C. L., \& Bogutchi, T. F. (2003). A evasão no ensino superior brasileiro: o caso da UFMG. Avaliação, 8(1), 161-189.

Biazus, C. (2004). Sistema de fatores que influenciam o aluno a evadir-se dos cursos de graduação na UFSM (Tese de Doutorado). Universidade Federal de Santa Catarina. Florianópolis, SC.

Bisinoto, G. D. S., \& Arenas, M. V. D. S. (2016). Gestão da Permanência: um estudo sobre o perfil socioeconômico, permanência e evasão dos discentes do Curso de Bacharelado em Administração Pública da UAB/UNEMAT. In: XVI Coloquio Internacional de Gestión Universitaria - CIGU. Arequipa, Peru.

Camelo Neto, G. (2014). Análise dos fatores da evasão discente de uma IES privada de Fortaleza-CE (Tese de Doutorado). Universidade Federal do Ceará, Programa de Pós-graduação em Políticas Públicas e Gestão da Educação Superior, Fortaleza (CE). 118p.

Canziani, I. F. S. (2015). Evasão dos cursos de pós-graduação lato sensu (2010-2014) da Universidade do Sul de Santa Catarina/UNISUL - Campus Sul, Tubarão/SC.

Castro, A. (2012). Evasão no ensino superior: um estudo no curso de psicologia da UFRGS. $2012.115 \mathrm{f}$ (Dissertação de Mestrado). Programa de Pós-graduação em Psicologia. Universidade Federal do Rio Grande do Sul, Porto Alegre).

Coordenação de Pessoal de Nivel Superior (CAPES). (2017).

Cornelio, R. A., Vasconcelos, F. C. W.,\& Goulart, I. B. (2016). Educação a distância: uma análise estatística dos fatores relacionados à evasão e à permanência. Revista Gestão Universitária na América Latina-GUAL, 9(4). DOI: https://doi.org/10.5007/1983-4535.2016v9n4p26 
Cunha, J. V. A. D. (2007). Doutores em Ciências Contábeis da FEA/USP: análise sob a óptica da teoria do capital humano. São Paulo (Tese de Doutorado). Programa de Pós-Graduação em Controladoria e Contabilidade, Departamento de Contabilidade e Atuária, Faculdade de Economia, Administração e Contabilidade da Universidade de São Paulo.

Díaz, O. E., Guajardo, D. C., Fiegehen, L. G., Campos, J. L., \& Grau, E. S. C. (2012). Fatores intraescolares associados ao abandono escolar no Chile: um estudo de caso. Revista Lusófona de Educação, (20), 47-64.

Durso, S. O. (2015). Características do processo de evasão dos estudantes do curso de Ciências Contábeis de uma Universidade Pública Brasileira. (Dissertação de Mestrado). Programa de Pós-graduação em Controladoria e Contabilidade. Faculdade de Ciências Econômicas, Universidade Federal de Minas Gerais, Belo Horizonte.

Feitosa, J. M. (2016). Análise de evasão no ensino superior: uma proposta de diagnóstico para o campus de laranjeiras. (Dissertação de Mestrado). Programa de Pós-graduação em Administração Pública. Universidade Federal de Sergipe.

Gama, E. N. K. (2015). Obstáculos à formação no ensino superior: um estudo da retenção discente nos cursos de graduação presencial do Centro de Artes da UFES (Dissertação de Mestrado). Programa de Pós-graduação em Gestão Pública. Universidade Federal do Espírito Santo).

Gilioli, R. D. S. P. (2016). Evasão em instituições federais de ensino superior no Brasil: expansão da rede, Sisu e desafios. Estudo Técnico - Câmara dos deputados.

Golde, C. M. (1998). Beginning graduate school: Explaining first year doctoral attrition. New directions for higher education, 1998(101), 55-64. DOI: http://dx.doi.org/10.1002/he.10105

Gonzalez, M. V. (2017). Estudio del abandono empleando un modelo de riesgos proporcionales. In: Congresos CLABES.

Gomes, A. A. (1998). Evasão e Evadidos: O discurso dos ex-alunos sobre evasão escolar nos cursos de licenciatura. 1998. 175 f (Tese de Doutorado). Programa de Pós-graduação em Educação da Universidade Estadual Paulista, Marília.

Gomes, K. A. (2015). Indicadores de permanência na educação superior: o caso da disciplina de Cálculo Diferencial e Integral I. Dissertação - Centro Universitário de La Salle, Canoas.

Lapini, V. C. (2012). Panorama da formação do professor em Ciências Contábeis pelos cursos stricto sensu no Brasil. (Dissertação de Mestrado). Ribeirão Preto, USP/RP.

Lima Júnior, P. (2013). Evasão do ensino superior de Física segundo a tradição disposicionalista em sociologia da educação. (Tese de Doutorado) Universidade Federal do Rio Grande do sul.

Lima, F. S., \& Zago, N. (2016). Evasão no Ensino Superior: tendências e resultados de pesquisa. XI Anped Sul Educação, movimentos sociais e políticas governamentais.

Machado, C., \& Szerman, C. (2017). Centralized Admissions and the Student-College Match. DOI: https://dx.doi. org/10.2139/ssrn.2844131

Martins, G. D. A., \& Theóphilo, C. R. (2016). Metodologia da investigação cientifica. São Paulo: Atlas.

Massi, L., \& Villani, A. (2015). Um caso de contratendência: baixa evasão na licenciatura em química explicada pelas disposições e integrações. Educação e Pesquisa, 41(4), 975-992. DOI: https://doi.org/10.1590/s15179702201512135667

Miranda, G. J., Nova, S. P. D. C. C., \& Cornacchione Júnior, E. B. (2012). Os Saberes dos Professores-Referência no Ensino de Contabilidade*/The Knowledge of Model Professors in Teaching Accounting. Revista Contabilidade \& Finanças, 23(59), 142. DOI: https://doi.org/10.1590/S1519-70772012000200006

Nagai, N. P., \& Cardoso, A. L. J. (2017). A evasão universitária: uma análise além dos números. Revista Estudo \& Debate, 24(1). DOI: http://dx.doi.org/10.22410/issn.1983-036X.v24i1a2017.1271

Palharini, F. (2004). Elementos para a compreensão do fenômeno da evasão na UFF. Avaliação, 9(2), 51-80.

Pascarella, E. T., \& Terenzini, P. T. (1980). Predicting freshman persistence and voluntary dropout decisions from a theoretical model. The journal of higher education, 51(1), 60-75. DOI: https://doi.org/10.1080/00221546. 1980.11780030 
Pereira, R. S., Zavala, A. A. Z.,\& Santos, A. C. (2014). Evasão na Universidade Federal de Mato Grosso. Revista de Estudos Sociais, 13(26), 74-86.

Rafael, J. A. M., Miranda, P. R. D., \& Carvalho, M. P. D. (2015). Análise da Evasão em um Curso de Licenciatura em Matemática da Rede federal de ensino nos seus primeiros cinco anos de implantação. Revista Paranaense de Educação Matemática, 4(6).

Rocha, C. S. (2015). Por que eles abandonam? evasão de bolsistas PROUNI dos cursos de licenciaturas. (Tese de Doutorado). Universidade do Vale do Rio dos Sinos, São Leopoldo.

Sales Junior, J. S. (2013). Uma Análise Estatística dos Fatores de Evasão e Permanência de Estudantes de Graduação Presencial da UFES (Dissertação de Mestrado). Programa de Pós-graduação em Gestão Pública. Universidade Federal do Espírito Santo.

Silva, G. P. (2013). Análise de evasão no ensino superior: uma proposta de diagnóstico de seus determinantes. Avaliação: Revista da Avaliação da Educação Superior, 18(2). DOI: https://doi.org/10.1590/S141440772013000200005

Silva, F. C. D. (2016). O desempenho acadêmico e o fenômeno da evasão em cursos de graduação da área da saúde. Congresso Brasileiro de Ensino em Engenharia. Natal. DOI: http://dx.doi.org/10.26512/2015.04.D.19947

Slhessarenko, M., Reis Gonçalo, C., Carlos Beira, J., \& Cembranel, P. (2014). A evasão na educação superior para o curso de bacharelado em sistema de informação. Revista Gestão Universitária na América Latina-GUAL, 7(1). DOI: https://doi.org/10.5007/1983-4535.2014v7n1p128

Spady, W. G. (1970). Dropouts from higher education: An interdisciplinary review and synthesis. Interchange, $1(1), 64-85$.

Spady, W. G. (1971). Dropouts from higher education: Toward an empirical model. Interchange, 2(3), 38-62. DOI: https://doi.org/10.1007/BF02282469

Tinto, V. (1975). Dropout from higher education: A theoretical synthesis of recent research. Review of educational research, 45(1), 89-125. DOI: https://doi.org/10.3102/00346543045001089

Tinto, V. (1993). Building community. Liberal Education, 79(4), 16-21.

Tinto, V. (1997). Classrooms as communities: Exploring the educational character of student persistence. The Journal of higher education, 68(6), 599-623. DOI: https://doi.org/10.1080/00221546.1997.11779003

Tontini, G., \& Walter, S. A. (2014). Pode-se identificar a propensão e reduzir a evasão de alunos? Ações estratégicas e resultados táticos para instituições de ensino superior. Avaliação: Revista da Avaliação da Educação Superior, 19(1). DOI: https://doi.org/10.1590/S1414-40772014000100005

Vergidis, D., \& Panagiotakopoulos, C. (2002). Student Dropout at the Hellenic Open University: Evaluation of the Graduate Program," Studies in Education". The International Review of Research in Open and Distributed Learning, 3(2). DOI: https://doi.org/10.19173/irrodl.v3i2.101

Villar, S. F. (2014). Evasão escolar no âmbito do Instituto Federal de Brasília. Revista Eixo, 3(2). DOI: https://doi. org/10.19123/eixo.v3i2.160

Vitelli, R. F. (2013). Evasão em cursos de licenciatura: perfil do evadido, fatores intervenientes no fenômeno. (Dissertação de Mestrado). Universidade do Vale do Rio dos Sinos, São Leopoldo.

Zewotir, T., North, D., \& Murray, M. (2015).The time to degree or dropout amongst full-time master's students at University of KwaZulu-Natal. South African Journal of Science, 111(9-10), 01-06. DOI: http://dx.doi. org/10.17159/SAJS.2015/20140298

\section{Como citar este artigo}

Pereira, V. H.; Cunha, J. V. A. da; Avelino, B. C.; \& Cornacchione Junior, B. E. (2021). Percepção de pósgraduandos sobre os motivos que contribuiriam para a evasão de estudantes dos cursos stricto sensu em contabilidade. Revista de Contabilidade e Organizações, 15:e182882. DOI: http://dx.doi.org/10.11606/ issn.1982-6486.rco.2021.182882 
Apêndice A - Perfil dos pós-graduandos da amostra

\begin{tabular}{|c|c|c|c|c|}
\hline \multirow{2}{*}{ Variável } & \multicolumn{2}{|c|}{ Mestrado } & \multirow{2}{*}{ Doutorado } & \multirow{2}{*}{ Total } \\
\hline & Acadêmico & Profissional & & \\
\hline Gênero & 390 & 57 & 172 & 619 \\
\hline Masculino & $172(44 \%)$ & $30(53 \%)$ & $80(47 \%)$ & $282(45 \%)$ \\
\hline Feminino & $217(56 \%)$ & $27(47 \%)$ & $90(52 \%)$ & $334(54 \%)$ \\
\hline Não desejo declarar & $1(0 \%)$ & $0(0 \%)$ & $2(1 \%)$ & $3(1 \%)$ \\
\hline Idade & 390 & 57 & 172 & 619 \\
\hline Entre 20 e 25 anos & $115(29 \%)$ & $1(2 \%)$ & $18(10 \%)$ & $134(22 \%)$ \\
\hline Entre 26 e 30 anos & $112(29 \%)$ & $11(19 \%)$ & $51(30 \%)$ & $174(28 \%)$ \\
\hline Entre 31 e 35 anos & $76(19 \%)$ & $17(30 \%)$ & $38(22 \%)$ & $131(21 \%)$ \\
\hline Entre 36 e 40 anos & $38(10 \%)$ & $7(12 \%)$ & $24(14 \%)$ & $69(11 \%)$ \\
\hline Entre 41 e 45 anos & $24(6 \%)$ & $5(9 \%)$ & $24(14 \%)$ & $53(9 \%)$ \\
\hline Acima de 45 anos & $25(6 \%)$ & $16(28 \%)$ & $17(10 \%)$ & $58(9 \%)$ \\
\hline Onde reside & 390 & 57 & 172 & 619 \\
\hline Na cidade de localização do curso & $264(68 \%)$ & $32(56 \%)$ & $111(65 \%)$ & $407(66 \%)$ \\
\hline Fora da cidade de localização do curso & $126(32 \%)$ & $25(44 \%)$ & $61(35 \%)$ & $212(34 \%)$ \\
\hline Concessão de bolsas & 390 & 57 & 172 & 619 \\
\hline Bolsistas & $163(42 \%)$ & $8(14 \%)$ & $68(40 \%)$ & $239(39 \%)$ \\
\hline Não bolsistas & $227(58 \%)$ & $49(86 \%)$ & $104(60 \%)$ & $380(61 \%)$ \\
\hline Trabalha ou não trabalha & 390 & 57 & 172 & 619 \\
\hline Trabalha & $235(60 \%)$ & $49(86 \%)$ & $120(70 \%)$ & $404(65 \%)$ \\
\hline Não trabalha & $155(40 \%)$ & $8(14 \%)$ & $52(30 \%)$ & $215(35 \%)$ \\
\hline Caso o estudante trabalhe, a empresa é de iniciativa: & 235 & 49 & 120 & 404 \\
\hline Privada & $127(54 \%)$ & $39(80 \%)$ & $36(30 \%)$ & $202(50 \%)$ \\
\hline Pública & $108(46 \%)$ & $10(20 \%)$ & $84(70 \%)$ & $202(50 \%)$ \\
\hline Renda mensal do grupo familiar & 390 & 57 & 172 & 619 \\
\hline Até um salário mínimo & $0(0 \%)$ & $1(2 \%)$ & $0(0 \%)$ & $1(0 \%)$ \\
\hline Entre um a dois salários mínimos & $40(10 \%)$ & $0(0 \%)$ & $10(6 \%)$ & $50(8 \%)$ \\
\hline Entre dois a cinco salários mínimos & $131(34 \%)$ & $3(5 \%)$ & $38(22 \%)$ & $172(28 \%)$ \\
\hline Entre cinco a dez salários mínimos & $113(29 \%)$ & $23(40 \%)$ & $65(38 \%)$ & $201(32 \%)$ \\
\hline Mais de dez salários mínimos & $106(27 \%)$ & $30(53 \%)$ & $59(34 \%)$ & $195(32 \%)$ \\
\hline Participa ou não da vida econômica familiar & 390 & 57 & 172 & 619 \\
\hline Participa & $283(73 \%)$ & $56(98 \%)$ & $147(85 \%)$ & $486(79 \%)$ \\
\hline Não participa & $107(27 \%)$ & $1(2 \%)$ & $25(15 \%)$ & $133(21 \%)$ \\
\hline
\end{tabular}

Fonte: elaborada pelos autores. 
Apêndice B - Notas atribuídas pelos diferentes perfis de estudantes considerando gênero, idade e bolsa

\begin{tabular}{|c|c|c|c|c|c|c|c|c|c|c|c|c|}
\hline \multirow{2}{*}{ Motivo } & \multicolumn{2}{|c|}{ Feminino } & \multicolumn{2}{|c|}{ Masculino } & \multicolumn{2}{|c|}{$\begin{array}{l}\text { Idade igual ou inferior à } \\
\text { mediana ( } 31 \text { anos) }\end{array}$} & \multicolumn{2}{|c|}{$\begin{array}{c}\text { Idade superior à } \\
\text { mediana }\end{array}$} & \multicolumn{2}{|c|}{ Bolsista } & \multicolumn{2}{|c|}{ Não bolsista } \\
\hline & Média & $\begin{array}{c}\text { Grau de } \\
\text { propensão }\end{array}$ & Média & $\begin{array}{c}\text { Grau de } \\
\text { propensão }\end{array}$ & Média & $\begin{array}{c}\text { Grau de } \\
\text { propensão }\end{array}$ & Média & $\begin{array}{c}\text { Grau de } \\
\text { propensão }\end{array}$ & Média & $\begin{array}{c}\text { Grau de } \\
\text { propensão }\end{array}$ & Média & $\begin{array}{c}\text { Grau de } \\
\text { propensão }\end{array}$ \\
\hline 1 & 4,5255 & Médio & 4,1844 & Médio & 4,4971 & Médio & 4,2130 & Médio & 4,3891 & Médio & 4,3579 & Médio \\
\hline 2 & 6,1351 & Alto & 5,7660 & Médio & 5,7427 & Médio & 6,2491 & Alto & 5,2469 & Médio & 6,4237 & Alto \\
\hline 3 & 5,0601 & Médio & 4,6525 & Médio & 5,0439 & Médio & 4,6968 & Médio & 5,1967 & Médio & 4,6947 & Médio \\
\hline 4 & 4,0390 & Médio & 3,7730 & Médio & 3,8099 & Médio & 4,0578 & Médio & 3,8117 & Médio & 3,9895 & Médio \\
\hline 5 & 4,0360 & Médio & 4,3759 & Médio & 4,0848 & Médio & 4,3610 & Médio & 4,0837 & Médio & 4,2868 & Médio \\
\hline 6 & 5,0450 & Médio & 4,4681 & Médio & 4,9737 & Médio & 4,5848 & Médio & 4,9205 & Médio & 4,7237 & Médio \\
\hline 7 & 4,8018 & Médio & 4,0177 & Médio & 4,5175 & Médio & 4,3935 & Médio & 4,5021 & Médio & 4,4368 & Médio \\
\hline 8 & 3,1231 & Médio & 2,7624 & Baixo & 2,9942 & Baixo & 2,9458 & Baixo & 3,1381 & Médio & 2,8684 & Baixo \\
\hline 9 & 2,8228 & Médio & 3,1809 & Médio & 2,8830 & Baixo & 3,1408 & Médio & 3,0000 & Baixo & 2,9974 & Baixo \\
\hline 10 & 4,0480 & Médio & 4,1206 & Médio & 4,1491 & Médio & 4,0108 & Médio & 4,3264 & Médio & 3,9368 & Médio \\
\hline 11 & 3,0030 & Médio & 3,2482 & Médio & 3,1842 & Médio & 3,0542 & Médio & 3,2469 & Médio & 3,0500 & Médio \\
\hline 12 & 2,5616 & Baixo & 2,4291 & Baixo & 2,5058 & Baixo & 2,5451 & Baixo & 2,4937 & Baixo & 2,5421 & Baixo \\
\hline 13 & 4,1832 & Médio & 3,9397 & Médio & 4,1140 & Médio & 4,0650 & Médio & 4,1381 & Médio & 4,0632 & Médio \\
\hline 14 & 3,1892 & Médio & 2,4929 & Baixo & 3,0643 & Médio & 2,6715 & Baixo & 3,2510 & Médio & 2,6605 & Baixo \\
\hline 15 & 3,8408 & Médio & 3,6560 & Médio & 3,8187 & Médio & 3,7256 & Médio & 3,7322 & Médio & 3,8053 & Médio \\
\hline 16 & 4,0751 & Médio & 3,8546 & Médio & 4,0614 & Médio & 3,8917 & Médio & 3,8787 & Médio & 4,0526 & Médio \\
\hline 17 & 3,3333 & Médio & 2,9965 & Baixo & 3,4006 & Médio & 2,9711 & Baixo & 3,4059 & Médio & 3,0842 & Médio \\
\hline 18 & 2,4024 & Baixo & 2,2518 & Baixo & 2,3567 & Baixo & 2,3141 & Baixo & 2,5732 & Baixo & 2,1895 & Baixo \\
\hline 19 & 5,8468 & Médio & 5,5922 & Médio & 5,4035 & Médio & 6,1661 & Médio & 4,6569 & Médio & 6,4289 & Alto \\
\hline 20 & 3,2432 & Médio & 3,2589 & Médio & 3,2632 & Médio & 3,2671 & Médio & 3,2636 & Médio & 3,2658 & Médio \\
\hline 21 & 4,6066 & Médio & 4,0638 & Médio & 4,2690 & Médio & 4,5126 & Médio & 4,7573 & Médio & 4,1395 & Médio \\
\hline 22 & 4,2643 & Médio & 3,9184 & Médio & 4,3830 & Médio & 3,8014 & Médio & 4,4142 & Médio & 3,9395 & Médio \\
\hline
\end{tabular}

Fonte: elaborada pelos autores. 
Apêndice C - Notas atribuídas pelos diferentes perfis de estudantes considerando trabalho, renda e residência

\begin{tabular}{|c|c|c|c|c|c|c|c|c|c|c|c|c|}
\hline \multirow{2}{*}{ Motivo } & \multicolumn{2}{|c|}{ Trabalha } & \multicolumn{2}{|c|}{ Não trabalha } & \multicolumn{2}{|c|}{$\begin{array}{l}\text { Renda de até cinco } \\
\text { salários mínimos }\end{array}$} & \multicolumn{2}{|c|}{$\begin{array}{l}\text { Renda superior a cinco } \\
\text { salários mínimos }\end{array}$} & \multicolumn{2}{|c|}{$\begin{array}{l}\text { Reside na cidade de } \\
\text { localização do curso }\end{array}$} & \multicolumn{2}{|c|}{$\begin{array}{l}\text { Reside fora da cidade } \\
\text { de localização do curso }\end{array}$} \\
\hline & Média & $\begin{array}{c}\text { Grau de } \\
\text { propensão }\end{array}$ & Média & $\begin{array}{c}\text { Grau de } \\
\text { propensão }\end{array}$ & Média & $\begin{array}{c}\text { Grau de } \\
\text { propensão }\end{array}$ & Média & $\begin{array}{c}\text { Grau de } \\
\text { propensão }\end{array}$ & Média & $\begin{array}{c}\text { Grau de } \\
\text { propensão }\end{array}$ & Média & $\begin{array}{c}\text { Grau de } \\
\text { propensão }\end{array}$ \\
\hline 1 & 4,3292 & Médio & 4,4465 & Médio & 4,7354 & Médio & 4,1641 & Médio & 4,2678 & Médio & 4,5660 & Médio \\
\hline 2 & 6,3366 & Alto & 5,2791 & Médio & 5,8341 & Médio & 6,0455 & Alto & 5,8698 & Médio & 6,1604 & Alto \\
\hline 3 & 4,5594 & Médio & 5,5070 & Médio & 6,0807 & Alto & 4,2172 & Médio & 4,5479 & Médio & 5,5425 & Médio \\
\hline 4 & 3,9554 & Médio & 3,8558 & Médio & 3,8610 & Médio & 3,9545 & Médio & 3,8452 & Médio & 4,0660 & Médio \\
\hline 5 & 4,3317 & Médio & 3,9767 & Médio & 4,1525 & Médio & 4,2399 & Médio & 4,1867 & Médio & 4,2500 & Médio \\
\hline 6 & 4,7104 & Médio & 4,9674 & Médio & 5,3857 & Médio & 4,4697 & Médio & 4,7641 & Médio & 4,8679 & Médio \\
\hline 7 & 4,4381 & Médio & 4,5070 & Médio & 4,6592 & Médio & 4,3510 & Médio & 4,3587 & Médio & 4,6604 & Médio \\
\hline 8 & 2,7847 & Baixo & 3,3256 & Médio & 3,4619 & Médio & 2,6970 & Baixo & 2,9017 & Baixo & 3,1085 & Médio \\
\hline 9 & 2,9455 & Baixo & 3,0977 & Médio & 3,0807 & Médio & 2,9520 & Baixo & 3,0713 & Médio & 2,8585 & Baixo \\
\hline 10 & 3,9851 & Médio & 4,2791 & Médio & 4,2018 & Médio & 4,0227 & Médio & 4,2187 & Médio & 3,8349 & Médio \\
\hline 11 & 2,9307 & Baixo & 3,4930 & Médio & 3,3139 & Médio & 3,0202 & Médio & 3,1351 & Médio & 3,1085 & Médio \\
\hline 12 & 2,4381 & Baixo & 2,6837 & Baixo & 2,7758 & Baixo & 2,3813 & Baixo & 2,4447 & Baixo & 2,6745 & Baixo \\
\hline 13 & 4,0842 & Médio & 4,1070 & Médio & 4,2511 & Médio & 4,0025 & Médio & 4,2138 & Médio & 3,8585 & Médio \\
\hline 14 & 2,6361 & Baixo & 3,3628 & Médio & 3,4574 & Médio & 2,5682 & Baixo & 2,8133 & Baixo & 3,0330 & Médio \\
\hline 15 & 3,8020 & Médio & 3,7302 & Médio & 3,9462 & Médio & 3,6818 & Médio & 3,8378 & Médio & 3,6604 & Médio \\
\hline 16 & 4,0322 & Médio & 3,8977 & Médio & 4,2422 & Médio & 3,8409 & Médio & 3,9705 & Médio & 4,0142 & Médio \\
\hline 17 & 3,0173 & Médio & 3,5674 & Médio & 3,5516 & Médio & 3,0152 & Médio & 3,1499 & Médio & 3,3208 & Médio \\
\hline 18 & 2,2376 & Baixo & 2,5256 & Baixo & 2,5650 & Baixo & 2,2096 & Baixo & 2,2752 & Baixo & 2,4575 & Baixo \\
\hline 19 & 6,4307 & Alto & 4,4558 & Médio & 5,2691 & Médio & 6,0126 & Alto & 5,6978 & Médio & 5,8349 & Médio \\
\hline 20 & 3,2797 & Médio & 3,2372 & Médio & 3,3498 & Médio & 3,2172 & Médio & 3,1622 & Médio & 3,4623 & Médio \\
\hline 21 & 4,0965 & Médio & 4,9070 & Médio & 4,7758 & Médio & 4,1540 & Médio & 4,1597 & Médio & 4,7972 & Médio \\
\hline 22 & 3,8738 & Médio & 4,5907 & Médio & 4,6009 & Médio & 3,8535 & Médio & 4,0418 & Médio & 4,2783 & Médio \\
\hline
\end{tabular}

Fonte: elaborada pelos autores. 


\section{Apêndice D - Questionário aplicado aos pós-graduandos}

\section{TERMO DE CONSENTIMENTO LIVRE E ESCLARECIDO}

Você está sendo convidado(a) a participar de um questionário intitulado "Determinantes do processo de evasão de estudantes dos programas de pós-graduação stricto sensu em Ciências Contábeis no Brasil”, parte integrante de uma pesquisa realizada por pesquisadores do Centro de Pós-Graduação em Contabilidade (Cepcon) da Universidade Federal de Minas Gerais (UFMG), tendo sido submetida e aprovada pelo Comitê de Ética em Pesquisa (CEP) da UFMG (CAAE nº 85109518.4.0000.5149).

Tem como objetivo identificar quais são os fatores determinantes do processo de evasão de estudantes dos programas de Pós-Graduação stricto sensu em Ciências Contábeis no Brasil. Você é livre para deixar de participar da pesquisa a qualquer momento sem nenhum prejuízo ou coação. A pesquisa possui como coordenadora responsável à professora Dra. Jacqueline Veneroso Alves da Cunha e o pesquisador Victor Hugo Pereira. Para requisitar os resultados do trabalho, ou para tirar qualquer dúvida, envie e-mail para: victorhpra@yahoo.com.br.

Caso deseje participar desta pesquisa, deve responder o questionário após este termo de consentimento livre e esclarecido. Em nenhum momento você será identificado. Os resultados da pesquisa serão publicados e ainda assim a sua identidade será preservada. Para responder a pesquisa você levará aproximadamente 10 minutos, e não terá nenhum gasto financeiro.

Agradecemos sua colaboração

Estou de acordo com os termos desta pesquisa

( ) Sim

( ) Não

\section{PRIMEIRA PARTE: INFORMAÇÕES DO PARTICIPANTE}

1. Curso em que está matriculado:

( ) Mestrado Acadêmico

( ) Mestrado Profissional

( ) Doutorado

2. Instituição a que pertence:

( ) Fipecafi - SP

( ) FUCAPE - ES

( ) FUCAPE - MA

( ) $\mathrm{FURB}-\mathrm{SC}$

( ) FURG - RS

( ) MACKENZIE - SP

( ) PUC - SP

( ) UEM - PR

（ ) UERJ - RJ

( ) UFBA - BA

( ) UFC - CE 

( ) UFES - ES
( ) $\mathrm{UFG}-\mathrm{GO}$
( ) UFMG - MG
( ) UFMS - MS
( ) UFPB - PB
( ) UFPE - PE
( ) UFPR - PR
( ) UFRGS - RS
( ) UFRJ - RJ
( ) UFRN - RN
( ) UFRPE - PE
( ) UFSC - SC
( ) UFU - MG
( ) UNB - DF
( ) UNIFECAP - BA
( ) UNIOESTE - PR
( ) UNISINOS - PR
( ) UNOCHAPECÓ - SC
( ) USP - SP
（ ） USP RIBEIRÃO PRETO - SP
( ) Outro:

3. Gênero:

( ) Masculino

( ) Feminino

( ) Não desejo declarar

4. Idade (em anos):

5. Estado Civil:

( ) Solteiro(a)

( ) Casado(a)

( ) Outros 
6. Qual a sua cor ou raça?

( ) Branca

( ) Preta

( ) Parda

( ) Amarela

( ) Indígena

7. Você reside na mesma cidade da localização do curso de pós-graduação stricto sensu que está fazendo?

( ) $\operatorname{Sim}$

( ) Não

8. Qual foi o tempo de intervalo (em meses) transcorrido entre a conclusão do curso de graduação (se mestrando) ou curso de mestrado (se doutorando) com o ingresso no curso de pós-graduação que está matriculado?

( ) Menos de 12 meses

( ) Entre 13 e 24 meses

( ) Entre 25 e 36 meses

( ) Mais de 37 meses

9. Você é bolsista?

( ) $\operatorname{Sim}$

( ) Não

10. A sua graduação é em:

( ) Ciências Contábeis

( ) Administração

( ) Economia

( ) Direito

( ) Outros

11. Você trabalha?

( ) $\mathrm{Sim}$

( ) Não

12. Caso trabalhe, a empresa é de iniciativa:

( ) Privada

( ) Pública

( ) Não trabalho 
13. Qual é a renda mensal do seu grupo familiar?

( ) Até um salário mínimo

( ) Entre um a dois salários mínimos

( ) Entre dois a cinco salários mínimos

( ) Entre cinco a dez salários mínimos

( ) Mais de dez salários mínimos

14. Você participa da vida econômica familiar atualmente (trabalha para o próprio sustento ou de seus parentes)?

( ) $\mathrm{Sim}$

( ) Não

15. Quantas pessoas incluindo você vivem da renda mensal de seu grupo familiar atualmente?

( ) Uma

( ) Duas ou três

( ) Quatro ou cinco

( ) Seis ou mais

16. Qual o nível de escolaridade do seu pai?

( ) Ensino fundamental incompleto

( ) Ensino fundamental completo

( ) Ensino médio incompleto

( ) Ensino médio completo

( ) Ensino superior incompleto

( ) Ensino superior completo

( ) desconheço o nível educacional do meu pai

17. Qual o nível de escolaridade da sua mãe?

( ) Ensino fundamental incompleto

( ) Ensino fundamental completo

( ) Ensino médio incompleto

( ) Ensino médio completo

( ) Ensino superior incompleto

( ) Ensino superior completo

( ) desconheço o nível educacional da minha mãe

18. Qual o principal motivo o levou a ingressar no curso de Mestrado ou Doutorado que está fazendo?

( ) Aptidão para a área acadêmica

( ) Aumento da remuneração 
( ) Gratuidade do curso

( ) Aprofundamento na área

( ) Adquirir novos conhecimentos

( ) Maior mobilidade profissional

( ) Maior empregabilidade

( ) Estabilidade profissional

( ) Maior produtividade

( ) Desenvolvimento de habilidades cognitivas

( ) Prestígio

( ) Mudança no estilo de vida

( ) Adquirir diferenciação profissional

( ) Adquirir respeitabilidade e reconhecimento acadêmico / profissional

( ) Falta de opção

19. Você pensa em abandonar o curso de Mestrado ou Doutorado que está fazendo?

( ) $\operatorname{Sim}$

( ) Não

\section{SEGUNDA PARTE: MOTIVOS QUE PROPICIAM O ABANDONO (EVASÃO)}

Atribua uma nota de 1 a 10 de acordo com a sua percepção se o fator contribuiria ou não para o nível de propensão a evadir do curso de pós-graduação stricto sensu que está cursando. Você poderá atribuir qualquer nota entre 1 e 10 . Uma nota 10 significa que você concorda totalmente com o motivo e nota 1 que você discorda totalmente.

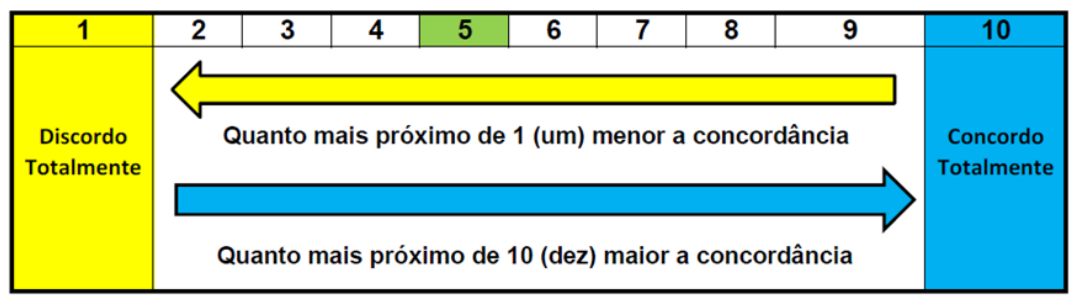

a) Dificuldades para acompanhar o conteúdo ministrado no curso. Nota:

b) Dificuldades para acompanhar o curso devido ao tempo necessário para os estudos. Nota:

c) Dificuldades para acompanhar o curso devido à falta de recursos financeiros. Nota:

d) Desempenho acadêmico insatisfatório. Nota:

e) Deficiência didática dos professores. Nota:

f) Falta de motivação em continuar no curso. Nota:

g) Dificuldades de adaptação ao curso. Nota:

h) Falta de integração social com os colegas do curso. Nota:

i) O currículo do curso é desatualizado. Nota:

j) O curso apresenta pouca ênfase em disciplinas de meu interesse. Nota:

k) Deficiência na infraestrutura da instituição. Nota: 
1) Perda de prestígio da carreira contábil. Nota:

m) $\mathrm{O}$ curso não era o que eu imaginava. Nota:

n) Percebi que não me sinto bem na profissão. Nota:

o) Falta de receptividade dos professores do curso. Nota:

Nota:

p) A instituição não disponibiliza o apoio necessário para que eu possa me adaptar ao ritmo do curso.

q) A profissão não permite que eu alcance o retorno financeiro que desejo. Nota:

r) Entrei no curso porque passei no processo de seleção, mas na verdade essa não foi a minha escolha. Nota:

s) Dificuldades para conciliar as atividades acadêmicas com as atividades profissionais. Nota:

t) Não foram disponibilizadas informações necessárias para que eu entendesse melhor o curso que ingressei. Nota:

u) Problemas de saúde. Nota:

v) Solidão durante o curso. Nota: 